\title{
Environmental Policy and Macroeconomic Dynamics in a New Keynesian Model*
}

\author{
Barbara Annicchiarico ${ }^{\dagger} \quad$ Fabio Di Dio ${ }^{\ddagger}$
}

July 2014

\begin{abstract}
This paper studies the dynamic behaviour of an economy under different environmental policy regimes in a New Keynesian model with nominal and real uncertainty. We find the following results: (i) an emissions cap policy is likely to dampen macroeconomic fluctuations; (ii) staggered price adjustment alters significantly the performance of the environmental policy regime put in place; (iii) the optimal environmental policy response to shocks is strongly influenced by the degree to which prices adjust and by the monetary policy reaction.
\end{abstract}

Keywords: New Keynesian Model, Environmental Policy, Macroeconomic Dynamics, Monetary Policy.

JEL codes: E32, E50, Q58.

\footnotetext{
${ }^{*}$ We would like to thank two anonymous referees for their very helpful comments and suggestions on an earlier version of this paper. We are also grateful to Christa Brunnschweiler, Luca Correani, Carolyn Fischer, Alessandra Pelloni, Lorenza Rossi, Simone Valente, and seminar participants at NTNU - Trondheim for useful discussions. The usual disclaimer applies.

${ }^{\dagger}$ Corresponding author: Università degli Studi di Roma "Tor Vergata", Dipartimento di Economia, Diritto e Istituzioni - Via Columbia 2 - 00133 Roma - Italy. E-mail: barbara.annicchiarico@uniroma2.it.

${ }^{\ddagger}$ Sogei S.p.a. - IT Economia - Modelli di Previsione ed Analisi Statistiche E-mail: fdidio@sogei.it.
} 


\section{Introduction}

This paper seeks to understand the importance of different environmental policy regimes as a further conditioning factor for the dynamic response of the economy to nominal and real shocks. To this end, we formulate a dynamic stochastic general equilibrium (DSGE) model of New Keynesian (NK) type embodying pollutant emissions and environmental policy.

The model that we construct has three key features. First, as in a standard NK model, the model embeds nominal price rigidities and monetary policy is described by a simple interestrate rule. ${ }^{1}$ In particular, nominal price rigidities stem from a time-dependent price-adjustment framework à la Calvo (1983), in which each period only a fraction of intermediate good producers are assumed to be able to change their prices, while the other fraction must satisfy all demand at the previously quoted prices. Second, for what concerns the real side of the economy, we depart from the very basic model by introducing capital accumulation and capital adjustment costs, so that our setup generates more plausible response of the main macrovariables to shocks and is more general, embodying a Real Business Cycle (RBC) model as a special case. Third, the model includes pollutant emissions which are a byproduct of output. Emissions are assumed to be costly to firms which are so pushed to limit the environmental impact of their production activity by undertaking abatement measures. Emissions and firms abatement activities depend on the type of environmental regime adopted, namely: cap-and-trade (i.e. an exogenous limit on aggregate emissions), emission intensity target (i.e. an exogenous limit on emissions per unit of aggregate output) and tax policy (e.g. a carbon tax).

With this characterization the paper asks the following questions: What is the impact of emissions regulations on the business cycle when we allow for imperfect price adjustment and monetary policy? To what extent do nominal rigidities influence the macroeconomic effects of the environmental policy regime put in place? How does environmental policy optimally respond to business cycle in the presence of nominal rigidities? What impact has the monetary regime on the optimal environmental policy response to shocks?

Preventing dangerous climate change is considered a priority of utmost importance by the international community. In this respect, a substantial cut of anthropogenic greenhouse gas

\footnotetext{
${ }^{1}$ See Woodford (2003) and Galí (2008).
} 
emissions at worldwide level is advocated as a means to keep global warming under control. From this perspective it is clear why over the last decades the debate on the relationship between economic growth and environmental policy has attracted increasing attention in academic and policy circles. The debate mainly focuses on how protection of environment and economic activity could be seen as mutually consistent and not as competing aims. ${ }^{2}$ However, at least in the short- to medium-term, environmental policy and economic activity are portrayed as being in conflict with one another and, as a consequence, the policy actions undertaken play an important role in making the trade-off between environmental quality and economic efficiency more or less painful. While regulations that manage to decouple environmental degradation from economic activity are less likely to affect the business cycle, climate actions are considered to have pervasive effects at macroeconomic level, since the additional costs of decarbonising an economy involve directly and/or indirectly both households and firms, changing their systems of incentives and, eventually, their attitude toward uncertainty and shocks. ${ }^{3}$ For instance, the commitment to a cap-and-trade scheme implies greater certainty about future emissions levels, but greater uncertainty about compliance costs, while intensity targets, allowing for fluctuations in aggregate emissions caused by fluctuations in economic activity, should reduce the uncertainty related to compliance costs. ${ }^{4}$ In this respect, our paper aims at contributing to the theoretical debate on this trade-off, by analyzing how alternative environmental policies are likely to condition the business cycle behavior of an economy whose equilibrium is distorted by the existence of imperfect competition and nominal rigidities.

A stream of empirical literature has made the case that slow price adjustment and monetary policy act as drivers of the business cycle, significantly altering the short-term course of the real economy (for an overview, see Clarida et al. 1999, Woodford 2003 and Galí 2008). For this reason nominal rigidities represent a key distortion in the NK models, where the emphasis is more on nominal shocks, rather than on productivity shocks, as drivers of economic fluctua-

\footnotetext{
${ }^{2}$ On the importance of approaching the issue of climate change from an economic perspective, the R.T. Ely lecture given by David Stern at the AEA 2008 Meeting represents a riveting introduction. See Stern (2008).

${ }^{3}$ Nevertheless, the regulatory response to climate change also presents significant opportunities with new markets and technologies developing as part of the slow transition toward a lower carbon economy.

${ }^{4}$ Intensity-based targets are expressed as pollutant emissions per unit of economic activity, which can be measured at an aggregate level, for example, in terms of GDP, or at a more detailed level, based on measures of firm's own output. In particular, indexing carbon dioxide emissions to GDP is considered an appealing option for developing economies.
} 
tions. ${ }^{5}$ In this context it is then possible to study the impact of environmental regulations from a different angle, where different sources of the business cycle may yield different outcomes, depending on how prices adjust to the changed economic conditions.

Our paper is related to the strand of literature that combines environmental economics and macroeconomics, aiming at a clear understanding of the interaction between environmental indicators and macroeconomic variables as well as of the potential effects of environmental regulations on the economy. ${ }^{6}$ In particular, the closest predecessors of our paper are those studying environmental policy in a DSGE framework. Prominent examples include Fischer and Springborn (2011), Heutel (2012), Angelopoulos et al. (2010, 2013) who study environmental policy in RBC models. ${ }^{7}$ In detail, Fischer and Springborn (2011) explore the macroeconomic performance of an emissions tax, an emissions cap and an intensity target in a RBC model in which production requires a polluting input, so that emissions abatement results from reductions in production in response to shocks and to the environmental policy regime put in place. ${ }^{8}$ They find that with respect to the no policy case, the variability of the main macroeconomic variables is lower under a cap and higher under a tax policy, while the two regimes perform similarly in terms of central tendencies, below those obtained in the no policy case. An intensity target, instead, is shown to produce higher mean values and lower welfare costs than other policies, with a volatility level not higher than that recorded with no policy. Heutel (2012) develops a RBC model in which emissions are a byproduct of production and firms are able to reduce pollutant emissions thank to a costly abatement technology they have at their disposal. In this framework the author shows that in a centralized economy the optimal environmental policy allows emissions to be procyclical; likewise, in a decentralized economy the optimal emissions

\footnotetext{
${ }^{5}$ Direct evidence on price rigidities is provided by Àlvarez et al. (2006), Bils and Klenow (2004), Dhyne et al. (2006), Klenow and Malin (2011), among others. In general, a marked heterogeneity in the frequency of price adjustment is found across sectors, while prices seem to change less frequently in Europe than in the United States.

${ }^{6}$ See Fischer and Heutel (2013) for a complete overview on the macroeconomic approach to the study of environmental related issues.

${ }^{7} \mathrm{~A}$ number of previous studies deal with the relationship between economic fluctuations and environmental policy, but not in the context of a RBC model. See e.g. Kelly (2005), Bouman et al. (2000).

${ }^{8}$ Starting with the seminal contribution of Weizman (1974), several other papers compare the performance of alternative environmental policies for regulating emissions, accounting or not for economic uncertainty, either in partial equilibrium settings (e.g. Hoel and Karp 2005, Newell and Pizer 2008, Quirion 2005 among others) or in general equilibrium models (e.g. Goulder et al. 1999, Parry and Williams 1999 Dissou 2005, Jotzo and Pezzey 2007).
} 
quota and the optimal taxation are found to move procycally. Finally, Angelopoulos et al. (2010) compare the performance of alternative environmental policy rules in a RBC model with uncertainty on total factor productivity, allowing also for exogenous shocks to the ratio of emissions to output, source of environmental uncertainty. In their model emissions are a byproduct of production, but only the government can engage in pollution abatement activity. The second-best policy prescription is found to depend crucially on whether environmental or technological uncertainty prevails. In a similar setup, Angelopoulos et al. (2013) demonstrate that the Ramsey government finds it optimal to cut taxes in response to a negative productivity shock in order to stimulate the economy, while in response to an adverse pollution shock it increases taxes to finance abatement spending in the attempt to mitigate the negative effects on the environment.

Starting from these contributions, we extend the analysis on the relationship between economic fluctuations and environmental policy in a framework that incorporates richer dynamics than in standard RBC models, along with two additional sources of uncertainty besides the standard total factor productivity shocks, namely public consumption shocks and monetary policy shocks.

To the best of our knowledge we are the first to explore the role of different environmental policy regimes as a further conditioning factor for the dynamic response of the economy to economic fluctuations in the presence of nominal rigidities and accounting for these additional sources of uncertainty. As a matter of fact, Fischer and Heutel (2013) already recognize that the NK-DSGE modeling approach represents a promising alternative tool for environmental policy analysis.

Our key findings are as follows. First, we find that a cap-and-trade is likely to dampen the response of the main macroeconomic variables to shocks, while emission permit price and firms' abatement effort react more strongly to the changed economic conditions. In particular, we show that the ability of the cap to dampen economic fluctuations, already found by Fischer and Springborn (2011), is particularly strong in the presence of nominal rigidities. Second, nominal rigidities are found to crucially alter the effects of the environmental policy regime adopted by introducing a certain degree of heterogeneity across firms. In this respect, we find 
that with nominal rigidities an intensity target environmental policy makes macroeconomic variables more volatile. Third, mean welfare tends to be slightly higher with a tax, provided that the degree of price stickiness is not too high, while its volatility is always lower with a cap-and-trade. On the other hand, if prices adjust very slowly, mean welfare will be higher under a cap-and-trade policy. In terms of welfare, the performance of an emissions intensity target is found to be significantly altered by the degree of price stickiness. Finally, the optimal environmental tax response to shocks is shown to be significantly affected by the degree to which prices adjust to the changed economic conditions and by the way in which monetary policy reacts to fluctuations. We derive our policy prescriptions under the assumption that a Ramsey planner optimally chooses environmental policy, considering different monetary policy regimes.

The structure of the paper is as follows. In Section 2 we outline the modified NK model extended to include pollutant emissions and abatement technology. Section 3 discusses the baseline calibration and the steady state properties of the model, considering alternative environmental policy regimes. In Section 4 we analyze the impulse response functions of the main macroeconomic variables to shocks and present the theoretical moments generated by the model, discriminating across different policy regimes. Section 5 shows how environmental policy optimally responds to shocks under different monetary policy regimes and for varying degree of nominal rigidities. Section 6 presents the main conclusions.

\section{The Model}

The economy is described by a standard NK model with nominal prices rigidities à la Calvo (1983), extended to account for pollutant emissions and environmental policy. Time is discrete and indexed by $t=0,1,2, \ldots$ The economy presents: (i) a continuum of monopolistically competitive polluting firms, each of which producing a single horizontally differentiated intermediate goods by using labor and physical capital as factor inputs; (ii) perfectly competitive firms combining domestically produced intermediate goods to produce a final consumption good; (iii) households who consume, offer labor services, and rent out capital to firms; (iv) a central bank making decisions on monetary policy; (v) a government deciding on fiscal and 
environmental policy.

\subsection{Final Good-Producing Firms}

We assume that firms producing final goods are symmetric and act under perfect competition. In each period the representative firm producing the final good $Y_{t}$ combines a bundle of differentiated intermediate goods $Y_{j, t}$, indexed by $j \in[0,1]$, according to a constant elasticity of substitution technology $Y_{t}=\left(\int_{0}^{1} Y_{j, t}^{\frac{\theta-1}{\theta}} d j\right)^{\frac{\theta}{\theta-1}}$, where $\theta>1$ denotes the elasticity of substitution between differentiated intermediate goods. Taking prices as given, the typical final good firm chooses intermediate good quantities $Y_{j, t}$ to maximize profits, resulting in the usual demand schedule: $Y_{j, t}=\left(P_{j, t} / P_{t}\right)^{-\theta} Y_{t}$, with $\theta>1$ being interpreted as the price elasticity of demand for good $j, P_{j, t}$ is the price of good $j$ and $P_{t}$ is the price of final good. Perfect competition and free entry drive the final good-producing firms' profits to zero, so that from the zero-profit condition we obtain $P_{t}=\left(\int_{0}^{1} P_{j, t}^{1-\theta} d j\right)^{\frac{1}{1-\theta}}$ which defines the aggregate price index of our economy.

\subsection{Intermediate Good-Producing Firms}

The intermediate goods sector is made by a continuum of monopolistically competitive polluting producers indexed by $j \in[0,1] .{ }^{9}$ The typical firm $j$ hires $L_{j, t}$ labor inputs and capital $K_{j, t}$ in perfectly competitive factor markets to produce the intermediate good $Y_{j, t}$, according to a constant-return to scale technology. In modeling emissions and abatement we follow Heutel (2012) and introduce a negative externality related to the deterioration of the environment, by assuming that the stock of pollutant affects productivity, so altering the production possibilities of firms. In particular, the production function is

$$
Y_{j, t}=\left(1-\Gamma\left(M_{t}\right)\right) A_{t} K_{j, t}^{\alpha} L_{j, t}^{1-\alpha}, \alpha \in(0,1)
$$

where $\Gamma$ is an increasing and convex function of the stock of pollution in period $t, M_{t}, \alpha$ is the elasticity of output with respect to capital and the term $A_{t}$ represents the level of technology

\footnotetext{
${ }^{9}$ Notably, the lack of competition is a source of inefficiency. Monopolistic competition, in fact, generates an average markup, which lowers the level of economic activity.
} 
(total factor productivity), which evolves according to the following process

$$
\log A_{t}=\left(1-\rho_{A}\right) \log A+\rho_{A} \log A_{t-1}+\varepsilon_{A, t},
$$

where $0<\rho_{A}<1$ and the serially uncorrelated shock $\varepsilon_{A, t}$ is normally distributed with mean zero and standard deviation $\sigma_{A}$.

Emissions at firm level, $Z_{j, t}$, are assumed to be proportional to output. ${ }^{10}$ However, this relationship is affected by the abatement effort $U_{j, t}$. In particular, we assume

$$
Z_{j, t}=\left(1-U_{j, t}\right) \varphi Y_{j, t}
$$

where $\varphi>0$ measures emissions per unit of output in the absence of abatement effort. The cost of emissions abatement $\mathcal{C}_{A}$ is, in turn, a function of the firm's abatement effort and output:

$$
\mathcal{C}_{A}\left(U_{j, t}, Y_{j, t}\right)=\phi_{1} U_{j, t}^{\phi_{2}} Y_{j, t}, \phi_{1}>0, \quad \phi_{2}>1
$$

where $\phi_{1}$ and $\phi_{2}$ are technological parameters of abatement cost.

Emissions are costly to producers and the unit cost of emission $P_{Z}$ depends on the environmental regime put into place. Clearly, in this context, the marginal cost of an additional unit of output has two components: the cost associated with the extra capital and labor inputs needed to manufacture the additional unit, which depends on the production technology and inputs' prices, and the costs associated with abatement and emissions, which depend on the available abatement technology and on the unit cost of emission.

Prices are modeled $\grave{a}$ la Calvo (1983). In each period there is a fixed probability $1-\xi$ that a firm in the intermediate sector is allowed to set its price optimally, otherwise its price stays unchanged. The probability of changing price $1-\xi$ is assumed to be independent of the time elapsed since the last adjustment. This price setting mechanism implies that the average price duration is given by $(1-\xi)^{-1}$.

From the solution of firm $j$ 's static cost minimization problem, taking the nominal wage rate

\footnotetext{
${ }^{10}$ This assumption is made for the sake of simplicity. Since the price setting mechanism introduces a source of heterogeneity across firms, some restrictive assumptions are needed to solve the aggregation problem.
} 
$W_{t}$, the rental cost of capital $R_{t}^{K}$ and unit cost of emission $P_{Z}$ as given, we have the following optimality conditions for the demand of labor, capital and the abatement effort, respectively:

$$
\begin{gathered}
(1-\alpha)\left(1-\Gamma\left(M_{t}\right)\right) A_{t} K_{j, t}^{\alpha} L_{j, t}^{-\alpha} \Psi_{j, t}=\frac{W_{t}}{P_{t}}, \\
\alpha\left(1-\Gamma\left(M_{t}\right)\right) A_{t} K_{j, t}^{\alpha-1} L_{j, t}^{1-\alpha} \Psi_{j, t}=\frac{R_{K, t}}{P_{t}} \\
\varphi \frac{P_{Z, t}}{P_{t}}=\phi_{1} \phi_{2} U_{j, t}^{\phi_{2}-1},
\end{gathered}
$$

where $\Psi_{j, t}$ is the marginal cost component related to the extra units of capital and labor needed to manufacture the additional unit of output and (7) equates the marginal value product of abatement (i.e. the cost saving related to lower emissions, $\varphi \frac{P_{Z, t}}{P_{t}} Y_{j, t}$ ) to its marginal cost (i.e. $\left.\phi_{1} \phi_{2} U_{j, t}^{\phi_{2}-1} Y_{j, t}\right)$. Conditions (5) and (6) imply that all firms choose the same capital-labor ratio, so that the marginal cost component $\Psi$, is common to all firms, namely ${ }^{11}$

$$
\Psi_{t}=\frac{1}{\alpha^{\alpha}(1-\alpha)^{1-\alpha}} \frac{1}{A_{t}\left(1-\Gamma\left(M_{t}\right)\right)}\left(\frac{W_{t}}{P_{t}}\right)^{1-\alpha}\left(\frac{R_{K, t}}{P_{t}}\right)^{\alpha}
$$

From (7) it emerges that also the abatement effort, $U_{j, t}$, is common to all firms. As a consequence the overall marginal cost of producing an additional unit of output is equal across firms, i.e.

$$
M C_{t}=\Psi_{t}+\phi_{1} U_{t}^{\phi_{2}}+\frac{P_{Z, t}}{P_{t}}\left(1-U_{t}\right) \varphi
$$

Consider now the optimal price setting problem of the typical firm $j$ which in period $t$ is able to reoptimize its price. Formally, the firm sets the price $P_{j, t}^{*}$ by maximizing the present discounted value of profits earned until it will be able to reset its price optimally again, subject to demand constraints $Y_{j, t+i}=\left(P_{j, t}^{*} / P_{t+i}\right)^{-\theta} Y_{t+i}$ for $i=0,1,2,3, \ldots$ and the available technology for production and abatement effort. In other words, a firm able to reset its price in period $t$ will choose to equate marginal revenue and marginal cost in a expected discounted value sense. The expected discounted value of real marginal revenues associated with a price changed in

\footnotetext{
${ }^{11}$ This can be seen by combining (5) with $(6)$ to obtain $\frac{K_{j, t}}{L_{j, t}}=\frac{W_{t}}{R_{K, t}} \frac{\alpha}{1-\alpha}$ which implies that all firms employ the same capital-labor ratio. Using this result back into (5), or into (6), yields the expression for $\Psi_{t}$.
} 
period $t$ is

$$
(1-\theta) E_{t} \sum_{i=0}^{\infty} \xi^{i} Q_{t, t+i}^{R}\left(\frac{P_{j, t}^{*}}{P_{t+i}}\right)^{-\theta} \frac{Y_{t+i}}{P_{t+i}}
$$

where $Q_{t, t+i}^{R}$ denotes the stochastic discount factor used at time $t$ by shareholders to value date $t+i$ real revenues and is related to the household's discount factor and the marginal utility of wealth $\lambda_{t}$, i.e. $Q_{t, t+i}^{R}=\beta^{i} \frac{\lambda_{t+i}}{\lambda_{t}}{ }^{12}$ The expected discounted value of real marginal costs stemming from a price change occurring at time $t$ is simply:

$$
-\theta E_{t} \sum_{i=0}^{\infty} \xi^{i} Q_{t, t+i}^{R} M C_{t+i}\left(\frac{P_{j, t}^{*}}{P_{t+i}}\right)^{-\theta-1} \frac{Y_{t+i}}{P_{t+i}} .
$$

By equating the dynamic marginal revenues to the dynamic marginal costs, we have the following optimal pricing condition:

$$
\frac{P_{t}^{*}}{P_{t}}=\frac{\theta}{\theta-1} \frac{E_{t} \sum_{i=0}^{\infty} \xi^{i} Q_{t, t+i}^{R} M C_{t+i}\left(\frac{P_{t+i}}{P_{t}}\right)^{\theta} Y_{t+i}}{E_{t} \sum_{i=0}^{\infty} \xi^{i} Q_{t, t+i}^{R}\left(\frac{P_{t+i}}{P_{t}}\right)^{\theta-1} Y_{t+i}}
$$

where we have dropped the $j$-index, since all firms able to set their price optimally at time $t$ will make the same decisions (see the Appendix for details).

It should be noted that in the limiting case of fully flexible prices (i.e. $\xi=0, P_{t}^{*}=P_{t}$ ), condition (12), given (9), collapses to

$$
M C_{t}=\frac{\theta-1}{\theta}=\Psi_{t}+\phi_{1} U_{t}^{\phi_{2}}+\frac{P_{Z, t}}{P_{t}}\left(1-U_{t}\right) \varphi
$$

according to which the real marginal cost of production $M C_{t}$ is constant. Note that this is equivalent to saying that in the absence of constraints on the frequency of price adjustment price markups are at the desired level $\theta /(\theta-1) .{ }^{13}$

Since in each period a fraction $1-\xi$ of firms choose their optimal money price $P_{t}^{*}$, the aggregate price level $P_{t}=\left(\int_{0}^{1} P_{j, t}^{1-\theta} d j\right)^{1 /(1-\theta)}$ (i.e. the price of the final good) evolves according to $P_{t}=\left[\xi P_{t-1}^{1-\theta}+(1-\xi) P_{t}^{* 1-\theta}\right]^{1 /(1-\theta)}$, that is to say that the price level is just a weighted average of the last period's price level and the price set by firms adjusting in the current

\footnotetext{
${ }^{12}$ The stochastic discount factor for nominal payoffs is, instead, defined as, $Q_{t, t+i}^{N}=\beta^{i} \frac{\lambda_{t+i}}{\lambda_{t}} \frac{P_{t}}{P_{t+i}}$.

${ }^{13}$ In the standard NK model we would have $M C_{t}=\Psi_{t}=\frac{\theta-1}{\theta}$.
} 
period. This equation can be rewritten as $1=\xi \Pi_{t}^{\theta-1}+(1-\xi)\left(p_{t}^{*}\right)^{1-\theta}$, where $\Pi_{t}=P_{t} / P_{t-1}$ is the gross inflation rate, measuring the evolution of the aggregate price level between $t$ and $t-1$, and $p_{t}^{*}=P_{t}^{*} / P_{t}$

\subsection{Households}

The representative infinitely-lived household maximizes the following lifetime utility:

$$
E_{t} \sum_{i=0}^{\infty} \beta^{t}\left(\log C_{t+i}-\mu_{L} \frac{L_{t+i}^{1+\phi}}{1+\phi}\right), \phi>0, \mu_{L}>0
$$

where $\beta \in(0,1)$ is the constant discount factor, $C_{t}$ represents consumption of the final good, $L_{t}$ denotes hours of work and $\mu_{L}$ weights the disutility of working and $\phi$ is the inverse of the Frisch elasticity. The period-by-period budget constraint of the typical household reads as

$$
P_{t} C_{t}+P_{t} I_{t}+Q_{t}^{N} B_{t}=B_{t-1}+W_{t} L_{t}+P_{t} D_{t}+R_{k, t} K_{t}-T_{t}-P_{t} \Gamma_{K}\left(I_{t}, K_{t}\right)
$$

where $B_{t}$ denotes the quantity of one-period nominal riskless bond purchased in period $t$ and paying one unit of money at maturity, $Q_{t}^{N}$ is the price of the bond, $B_{t-1}$ denote bond holdings at the beginning of period $t$ (carried from $t-1$ ), $T_{t}$ represents lump-sum taxes (or transfers from the government), $D_{t}$ are dividends from ownership of intermediate goods-producing firms, $W_{t} L_{t}$ denotes labor income and $R_{k, t} K_{t}$ is the rental (nominal) income from capital services. In each period $t$ the representative household carries $K_{t}$ units of physical capital from the previous period and makes investment decisions $I_{t}$, facing convex capital adjustment costs $\Gamma_{K}\left(I_{t}, K_{t}\right)$, given by $\frac{\gamma_{I}}{2}\left(\frac{I_{t}}{K_{t}}-\delta_{K}\right)^{2} I_{t}$ with $\gamma_{I}>0 .{ }^{14}$ Investment increases the household's stock of capital according to

$$
K_{t+1}=\left(1-\delta_{K}\right) K_{t}+I_{t}
$$

where $\delta_{K} \in(0,1)$ is the depreciation rate of capital. At the optimum the following conditions

\footnotetext{
${ }^{14}$ Convex adjustment costs imply that investments are less costly when spread out over a large time interval than when concentrated in a single period of time.
} 
must hold

$$
\begin{gathered}
R_{t}^{-1}=Q_{t}^{N}=\beta E_{t} \frac{P_{t}}{P_{t+1}} \frac{C_{t}}{C_{t+1}} \\
\mu_{L} L_{t}^{\phi}=\frac{1}{C_{t}} \frac{W_{t}}{P_{t}} \\
\beta E_{t} \frac{1}{C_{t+1}}\left[\frac{R_{k, t+1}}{P_{t+1}}+\gamma_{I}\left(\frac{I_{t+1}}{K_{t+1}}-\delta_{k}\right)\left(\frac{I_{t+1}}{K_{t+1}}\right)^{2}\right]-\frac{q_{t}}{C_{t}}+\beta\left(1-\delta_{k}\right) E_{t} \frac{q_{t+1}}{C_{t+1}}=0, \\
q_{t}-1-\gamma_{I}\left(\frac{I_{t}}{K_{t}}-\delta_{K}\right) \frac{I_{t}}{K_{t}}-\frac{\gamma_{I}}{2}\left(\frac{I_{t}}{K_{t}}-\delta_{K}\right)^{2}=0,
\end{gathered}
$$

where we have used the fact that $Q_{t}^{N}$ is the price of a risk-free bond paying one unit of the numéraire in period $t+1$, so that $Q_{t}^{N}=R_{t}^{-1}$, with $R_{t}$ being the risk free gross nominal interest rate, while $q_{t}$ measures the relative marginal value of installed capital with respect to consumption (i.e. the Tobin's q). The solution to the typical household's problem is described in the Appendix.

\subsection{Public Sector and Environmental Policy Regimes}

The monetary authority manages the short-term gross nominal interest rate $R_{t}$ in response to changes in the gross inflation rate $\Pi_{t}$ according to the following simple interest-rate rule:

$$
\frac{R_{t}}{R}=\left(\frac{\Pi_{t}}{\Pi}\right)^{\iota \pi} \eta_{t}
$$

where $R$ and $\Pi$ denote the corresponding deterministic steady-state values of the two relevant gross rates, $\iota_{\pi}>1$ is a policy parameter and $\eta_{t}$ is a monetary policy shock which, in turn, follows a stationary $\mathrm{AR}(1)$ process given by

$$
\log \eta_{t}=\rho_{\eta} \log \eta_{t-1}+\varepsilon_{\eta, t}
$$

where $0<\rho_{\eta}<1$ and the serially uncorrelated money supply shock $\varepsilon_{\eta, t}$ is normally distributed with mean zero and standard deviation $\sigma_{\eta}$. 
For simplicity we abstract from other arguments in the interest-rate rule, working under the assumption that the monetary authority has only a mandate for price stability. According to $(21)$, the gross nominal interest rate $R_{t}$ deviates from its steady-state level $R$ in response to inflation deviations from its own steady-state target value $\Pi$. The policy parameter $\iota_{\pi}$ is usually set larger than one, so that the monetary authority will react to inflation by increasing the nominal interest rate by more than proportionally, inducing, by virtue of the Fisher equation, a corresponding increase in the real interest rate, so being able to influence consumption and investment decisions and, hence, output. ${ }^{15}$

We assume that the net supply of bonds is zero, hence the flow budget constraint of the public sector simply reads as

$$
T_{t}+P_{Z, t} Z_{t}=P_{t} G_{t}
$$

where public consumption $G_{t}$ is fully financed by lump-sum taxes and revenues on emissions which depend on the environmental policy. The term $P_{Z, t} Z_{t}$ may, in fact, reflect the revenues from a tax policy or from the government sale of emissions permits. We assume that government consumption follows a stochastic process of the form:

$$
\log G_{t}=\left(1-\rho_{G}\right) \log G+\rho_{G} \log G_{t-1}+\varepsilon_{G, t}
$$

where $0<\rho_{G}<1$ and the serially uncorrelated money supply shock $\varepsilon_{G, t}$ is normally distributed with mean zero and standard deviation $\sigma_{G}$.

In what follows we will consider four different environmental policy regimes:

- No policy: emissions are costless to firms, (i.e. $P_{Z, t}=0$ ) and there is no incentive to sustain the costs of emission abatement, i.e. $U_{t}=0$.

- Cap-and-trade: $Z_{t}$ is fixed and the government sells emission permits to the producers at the market price $P_{Z, t}$.

- Intensity target: there is a binding emission target of $v<\varphi$ per unit of final output

\footnotetext{
${ }^{15}$ This interpretation of the above rule immediately follows by expressing it in terms of (net) rates. Let $r_{t}$ and $\pi_{t}$ denote the nominal interest rate and the inflation rate, respectively, and $r$ and $\pi$, be their steady-state counterparts, then (21) can be expressed as: $r_{t}-r=\iota_{\pi}\left(\pi_{t}-\pi\right)+\log \eta_{t}$, where we have used the standard approximations $\log \left(1+r_{t}\right) \simeq r_{t}, \log \left(1+\pi_{t}\right) \simeq \pi_{t}$.
} 
$\left(Z_{t}=v Y_{t}\right.$ for all $\left.t=0,1,2,3, \ldots\right)$ and the government sells emission permits to the producers at the market price $P_{Z, t}{ }^{16}$

- Tax policy: the government levies taxes on emissions at a constant (real) rate $\tau_{Z}$, implying that $p_{Z, t}=P_{Z, t} / P_{t}=\tau_{Z}$, so that condition (7) now reads as $\varphi \tau_{Z}=\phi_{1} \phi_{2} U_{t}^{\phi_{2}-1}$ and the abatement effort of intermediate-good producers is constant. ${ }^{17}$

\subsection{Aggregation, Equilibrium and Emissions}

In equilibrium factors and goods markets clear, hence the following conditions are satisfied for all $t: L_{t}=\int_{0}^{1} L_{j, t} d j, K_{t}=\int_{0}^{1} K_{j, t} d j$ which, in turn, imply that the aggregate production of intermediate goods can be expressed as $\int_{0}^{1} Y_{j, t} d j=\left(1-\Gamma\left(M_{t}\right)\right) A_{t} K_{t}^{\alpha} L_{t}^{1-\alpha}$. Using the fact that demand for each $j$ variety of intermediate good is given by $Y_{j, t}=\left(P_{j, t} / P_{t}\right)^{-\theta} Y_{t}$, by aggregation we have $\int_{0}^{1} Y_{j, t} d j=\int_{0}^{1}\left(P_{j, t} / P_{t}\right)^{-\theta} Y_{t} d j=Y_{t} D_{p, t}$, where $D_{p, t}=\int_{0}^{1}\left(P_{j, t} / P_{t}\right)^{-\theta} d j$ is a measure of price (and so of output) dispersion, which, given the constraint on price adjustment, evolves according to a non-linear first-order difference equation: $D_{p, t}=(1-\xi) p_{t}^{*-\theta}+\xi \Pi_{t}^{\theta} D_{p, t-1}$. It follows that total production of the final good is equal to

$$
Y_{t}=\left(1-\Gamma\left(M_{t}\right)\right) A_{t} K_{t}^{\alpha} L_{t}^{1-\alpha}\left(D_{p, t}\right)^{-1}
$$

It should be noted that the price dispersion term $D_{p, t}$ is generated by the Calvo's price staggering and is bounded below at one (see e.g. Galí 2008 for details). The higher the degree of price rigidities, the higher the price dispersion of the economy in response to shocks. This price dispersion term generates a wedge between aggregate output and intermediate inputs, making aggregate production less efficient.

The resource constraint of the economy reads as

$$
Y_{t}=C_{t}+I_{t}+G_{t}+\mathcal{C}_{A, t}+\frac{\gamma_{I}}{2}\left(\frac{I_{t}}{K_{t}}-\delta_{K}\right)^{2} I_{t},
$$

\footnotetext{
${ }^{16}$ Despite that we consider an intensity target in terms of final output, this translates into a common emissions intensity target at intermediate good producing firms' own output when the economy is in steady state, while preserving the possibility for firms to temporarily deviate from their targets in response to shocks, provided that the intensity target is met at aggregate level.

${ }^{17}$ One could also consider a setting in which the tax on emissions is set in nominal terms, i.e. $P_{Z, t}=\tau_{Z}$. We leave this hypothesis for future investigations.
} 
where part of the output goes in the capital adjustment cost and in the abatement cost $\mathcal{C}_{A, t}$ which depends on the environmental policy put in place. The aggregate abatement cost is obtained from (4) as follows:

$$
\mathcal{C}_{A, t}=\phi_{1} U_{t}^{\phi_{2}} \int_{0}^{1} Y_{j, t} d j=\phi_{1} U_{t}^{\phi_{2}} Y_{t} D_{p, t}
$$

Finally, we assume that emissions accumulate in the environment. Let $M_{t}$ denote the pollution stock at the end of period $t$, and $Z_{t}^{*}$ denotes the emissions of the rest of the world, then we have that the following accumulation equation holds

$$
M_{t}=\left(1-\delta_{M}\right) M_{t-1}+Z_{t}+Z_{t}^{*}
$$

where $\delta_{M}$ measures the fraction of pollution which naturally decays in each time period and aggregate emissions, $Z_{t}$, are related to the final output according to the equation:

$$
Z_{t}=\int_{0}^{1} Z_{j, t} d j=\left(1-U_{t}\right) \varphi \int_{0}^{1} Y_{j, t} d j=\left(1-U_{t}\right) \varphi Y_{t} D_{p, t} .
$$

In the Appendix we summarize the equations of the model and formally define the competitive equilibrium of the economy under study. However, before turning to the numerical solution of the model a couple of remarks are needed.

The first remark refers to the fact that the economy described by this model features some sources of inefficiencies that make the competitive equilibrium distorted and provide a rationale for the conduct of monetary and environmental policies. The first source of inefficiency is to be attributed to the existence of monopolistically competitive intermediate-good producers which generates positive markups lowering the level of economic activity. The second source of inefficiency, instead, is due to price rigidities, here introduced according to the Calvo setting. As already pointed out, this pricing assumption gives rise to price dispersion which, in turn, creates an inefficiency loss, since the higher is price dispersion the more intermediate goods are needed to produce a given level of final output. Since in this model pollution is proportional to intermediate goods production, we will see the non-trivial implications of this pricing assump- 
tion on the dynamics of the environmental variables. Finally, the third source of inefficiency is the one that differentiates the present model from a standard NK model, i.e. the presence of a negative externality of pollution on production.

The second remark concerns the dynamics implied by the three different environmental regimes in this economy. From (29) we observe that to meet the emission goal under a cap-andtrade, the abatement effort $U_{t}$ will need to be responsive to shocks. Under a tax policy, instead, the abatement effort and the marginal costs associated with abatement and emissions will be constant, therefore any change in output and in the price dispersion will induce a proportional movement in emissions. This is why, in this setting, from a purely dynamic perspective, under a tax policy the economy will behave as in the absence of any environmental regulation. ${ }^{18}$ Under an intensity target, instead, the emissions equation (29) boils down to $v=\left(1-U_{t}\right) \varphi D_{p, t}$, where the abatement effort needs to change over time in response to shocks as long as the inefficiency loss due to price dispersion is present, otherwise, as in the tax case, the abatement effort would be constant. That is why under flexible prices, given a common emissions goal, the tax policy and the intensity target give rise to the same results and the dynamics follow those of the no policy scenario. ${ }^{19}$

\section{Calibration and Deterministic Steady State}

In this section we summarize the parametrization of the model which is in line with the existing literature. $^{20}$ Time is measured in quarters. Table 1 lists the choice of parameter values for our baseline model.

The conventional parameters related to the NK structure of the model are standard. It should be mentioned that the scale parameter $\mu_{L}$ measuring labor disutility is calibrated in order to get, in the no-policy scenario, a steady state value of labor equal to 0.2 . Public consumption

\footnotetext{
${ }^{18}$ Notice that in Fischer and Springborn (2013) emissions are equal to the use of intermediate goods and there is a permit allocation mechanism which may vary with output according to the policy regime chosen. In their model an intensity target implies a one-to-one relationship between emissions and output as in the no policy scenario case, but not under a tax regime. In our model, instead, the intensity target displays the same dynamics of the no policy case only under flexible prices.

${ }^{19}$ Similarly, were the intensity defined as a function of the intermediate producers own output, rather than as a function of the final output, $(29)$ would boil down to $v=\left(1-U_{t}\right) \varphi$.

${ }^{20}$ See, for instance, Galí (2008).
} 
to GDP ratio $G / Y$ is set at 0.1022 , so that steady-state private consumption amounts to $70 \%$ of total output in the no-policy scenario. The steady-state target inflation is equal to zero $(\Pi=1)$, so abstracting from the presence of trend inflation.

Turning to the calibration regarding emissions, we set the parameter $\delta_{M}$ as in Heutel (2012); the coefficient $\varphi$, measuring emissions per unit of output, is set at 0.45 , consistently with the carbon dioxide emissions, expressed as kilos per 2005 PPP $\$$ of GDP ${ }^{21}$ and recorded by the US in 2005 according to the World Bank Indicators. The no-policy initial stock of carbon dioxide in the atmosphere, $M$, is set at 800 (consistently with the carbon mass of about 800 gigatons in 2005). Since according to the World Bank US emissions accounted for 0.208 of total world emissions, the steady-state value of $Z$ immediately follows. From equation (29), we then get the implied level of output in the no-policy scenario. The damage function $\Gamma\left(M_{t}\right)$ is assumed to be quadratic, $\Gamma\left(M_{t}\right)=\gamma_{0}+\gamma_{1} M_{t}+\gamma_{2} M_{t}^{2}$, and since the model is calibrated so as to yield pollution stock in gigatons, we can safely borrow the estimation made by Heutel (2012) for the US economy. ${ }^{22}$

In the three policy scenarios, namely the tax policy, cap-and-trade and the intensity target, the model is solved under the assumption that emissions are cut by $20 \%$, which is a reduction target of greenhouse gases emissions often considered in policy circles. ${ }^{23}$

The parameter $\phi_{2}$ of the abatement cost function is as in Nordhaus (2008), while the scale coefficient $\phi_{1}$ is calibrated so as to have an abatement cost to output ratio equal to $0.15 \%{ }^{24}$ Note that in the case of intensity target the parameter measuring the binding emission target as a share of output, $v<\varphi$, is set consistently with an emission reduction with respect to the benchmark no-policy scenario of $20 \%$. As a consequence of this assumption, the three policy scenarios have the same deterministic steady state. This calibration strategy facilitates the comparison across environmental policy regimes.

Finally, the persistence of the exogenous processes $A_{t}, G_{t}$ and $\eta_{t}$ the standard deviations of

\footnotetext{
${ }^{21}$ Equivalently, gigatons per 2005 PPP trillions \$ of GDP.

${ }^{22}$ Given this calibration, the output loss due to the deterioration of the environment is equal to $0.26 \%$.

${ }^{23}$ See, for instance, the Europe 2020 strategy headline reduction target of $20 \%$ (from 1990), consistently with the EU's Kyoto emissions goal or the debated proposal for the US put forward by Waxman of a reduction by up to $20 \%$ below 2005 levels by 2020 .

${ }^{24}$ The amount of this cost will depend on the particular abatement technologies available to firms. On the measurement of the economic burden of environmental regulation, see Pizer and Kopp (2005).
} 
the innovations are set as in Smets and Wouters (2007).

Given this parametrization, the deterministic steady state and the implied values for all relevant macrovariables in the no policy scenario and in the three policy scenarios are reported in Table 2, where we have defined $p_{Z}=P_{Z} / P$. As expected, the level of economic activity turns out to be lower under the three policy scenarios as a consequence of the additional costs of the environmental regulation borne by producers. In particular, it should be noted that, despite that abatement costs amount to only $0.15 \%$ of output in the regulated regime, a $20 \%$ reduction of emissions is associated with a $2.42 \%$ reduction of output. This effect on output is due to the fact that intermediate-good producing firms, facing the extra costs related to the environmental policy, will find it optimal to reduce the costs associated with labor and capital by producing less. In equilibrium this lower output will be associated to lower levels of consumption and investments. In the new equilibrium the fraction of productivity loss due to the deterioration of the climate condition reduces by -0.0542 percentage points (p.p). However, this beneficial effect of the environmental policy will fully materialize only after several decades.

In the new steady state, the welfare cost of achieving a lower level emissions amounts to $1.3109 \%$. As common practice in the DSGE literature this welfare cost is measured in consumption equivalent units, namely as the percentage reduction in discounted quarterly consumption with respect to the no policy case that would be necessary to make a representative consumer indifferent between a no policy scenario and one characterized by emissions regulations. However, since the stock of pollution converges very slowly to the new steady state and there is a significant lag between the timing of emissions and the materialization of the damages associated to climate changes, a correct welfare comparison requires to evaluate the welfare costs during the transition dynamics toward the new steady state, starting from a no policy scenario and looking at the present value utility for different time horizons. In a 30-year time horizon evaluation the decrease of quarterly consumption from the no policy case, to replicate the present value of utility under the regulated regime, is $0.52 \%$ for the tax and for the intensity target, and $0.53 \%$ for the cap-and-trade. If we consider a shorter time horizon, say 10 years, then we observe welfare benefits amounting to $0.28 \%$ for the tax and the intensity target and to $0.27 \%$ for the cap-and-trade. This result can be easily explained by the fact that the advent 
of environmental regulation has an initial positive impact on consumption, since the revenues of emissions permits are redistributed to households. Overall we observe that the welfare costs are virtually identical for the three environmental regimes also along the transition and that are much lower than the welfare costs computed by comparing steady-state values. Notice that our results differ from those obtained by Fischer and Springborn (2011), who show that in a 30-year time horizon the welfare costs under the intensity target are higher than those observed in the case of tax and cap, but lower if computed in the new steady state. This difference is to be ascribed to the way in which emissions are modelled in our model, rather than to the presence of other frictions, which, instead, are likely to shape the behavior of the economy only in the short run and in the presence of uncertainty.

\section{Dynamics under Different Environmental Policy Regimes}

In this Section we analyze the dynamic properties of the model under alternative environmental policies (no policy, cap-and-trade, intensity target and tax policy). To this end we first look at the equilibrium response of a number of macroeconomic variables of interest to three temporary shocks typically considered in the literature: a shock to technology, government consumption and the nominal interest rate. Finally, to further assess the implications of different environmental regimes, we compute the moments of the key macroeconomic variables, given the same three sources of uncertainty under different degrees of price rigidities. All the simulation results for the competitive economy have been obtained by using a 'pure' perturbation method which amounts to a second-order Taylor approximation of the model around its deterministic steady state. $^{25}$

\footnotetext{
${ }^{25}$ See Judd (1998) and Schmitt-Grohé and Uribe (2004). The model has been solved in Dynare. For details, see http://www.cepremap.cnrs.fr/dynare/ and Adjemian et al. (2010). Second-order approximations are more accurate and allow us to account for the effects of uncertainty. However, a correct application of the perturbation method requires the model to be solved around its steady state, implying that also in the three policy scenarios we have to explore the business cycle properties of the economy in the neighborhood of the new steady state, which, as already remarked, is far in the future.
} 


\subsection{Technology Shock}

Figure 1 displays the economy's response to a one percent increase in productivity $A_{t}$ under four different environmental policy scenarios: no policy and cap-and-trade (panel a), intensity target and tax policy (panel b). All results are reported as percentage deviations from the initial steady state over a 20-quarter period.

Following a positive technology innovation, as expected, output, consumption, investment and labor all rise persistently. Clearly, the higher productivity brings about a fall of firms' marginal costs. It should be noted that the reaction of labor is positive, despite that the presence of price rigidities prevents intermediate-good producers from fully adjusting their prices downward to the new lower level of marginal costs. ${ }^{26}$ Since the beneficial effects of a positive innovation on productivity are temporary, households will find it optimal to build up the capital stock and to work harder during the early phases of the adjustment process, when productivity is higher. This also explains why consumption follows a hump-shaped dynamics in response to the shock. Turning now to the dynamic implications of the environmental policy regimes put in place, we observe that the cap-and-trade policy slightly diminishes the response of output, consumption, investment and labor. Intuitively, the emission cap, by pegging the aggregate level of pollutant emissions, forces firms increasing their production to sustain higher abatement costs. These higher costs, in turn, will diminish the level of output available for consumption and investment, so implying a milder expansion of these variables. On the other hand, with an intensity target environmental regime, emissions will expand with output, while with a tax policy firms will be able to increase pollutant emission at a constant marginal cost, so the dynamic behavior of the economy would mimic that observed under a no policy regime.

Consider now the dynamics of the emissions related variables. Obviously, the increase in productivity induces a corresponding increase in emissions, since we assume a proportional relationship between output and emissions, as equation (29) reads, with no significantly differences among the tax policy, the intensity target regime and the no policy scenario. The only exception is given by the cap-and-trade regime where, instead, the adjustment to the positive

\footnotetext{
${ }^{26}$ The negative response of labor to a positive productivity shock emerges in basic NK models without capital accumulation, where price rigidities push producers to take advantage of the productivity increase by reducing labor demand (see e.g. Galí 2008). Here the behavior of the economy is closer to that of a typical RBC model, because of the presence of capital.
} 
technology shock calls for a substantial reaction of the abatement effort in order to fully keep the target level of emissions. The abatement costs increase more than proportionally with respect to output as a consequence of the assumed convex abatement technology. As a result, the permit price goes up, reflecting the relative effort of the government in sustaining the emission cap. The more resources devoted to the pollutant abatement will diminish the expansionary effect of the positive innovation to technology.

Under a tax policy the permit price is constant, and so also the firms' abatement effort. As already remarked, from a purely dynamic point of view the economy behaves like in the no policy scenario. Finally, looking at the response of these macrovariables under an intensity target rule, we notice that, at least initially, both the abatement effort and the permit price positively react in response to the shock, although the measure of this reaction is quite small in size. To understand why the abatement effort and the permit price initially increase also in the case of emission intensity, one should consider the behavior of the firms able to adjust their prices in response to the positive technology shock. Since marginal costs are lower, firms will find it optimal to cut prices to increase the demand. Given the existence of nominal rigidities, only a fraction of firms will be able to cut prices, so expanding the demand of their production by more than under the flexible price case. As a result, these producers will expand their output by more than the other firms. This heterogeneity of firms' behavior is summarized by the aggregate emission equation (29). Under an emission intensity policy (29) boils down to $v=\left(1-U_{t}\right) \varphi D_{p, t}$, so implying that even for a given emission to output ratio, there is room for a time-varying abatement effort, which is however always equal across firms. This result is due to two main characteristics of this economy, namely (i) the Calvo's pricing assumption, that gives rise to price dispersion which, in turn, creates an efficiency loss, because the higher is price dispersion the more intermediate (polluting) goods are needed to produce a given level of final good; (ii) the fact that the intensity target is set in terms of the final good and not as a function of the intermediate good producer's own output. Following the shock, in fact, the price dispersion $D_{p, t}$ will increase, implying that more polluting intermediate goods will be needed to produce a unit of final output, so requiring a higher abatement to meet the intensity target. Clearly, this higher abatement effort will translate into a slightly lower initial response 
of the emissions to the expansionary shock than that observed under a tax policy.

\subsection{Public Consumption Shock}

We now consider the economy's response to a positive demand shock. In particular, we focus our attention on a positive innovation to public consumption $G$. Figure 2 illustrates the impulse responses of the economy to this shock under the four different environmental policy regimes.

Following the shock, output and labor increase, although the size of their response is negligible. As expected, this shock triggers a decrease of private consumption and investment which are crowded out by the higher government spending. Intuitively, in response to this shock, wealth effects are expected to drive the behavior of consumption and investment: following a public expenditure increase agents feel poorer because less resources are available for private use. As a result, they will tend to work harder to offset the decreasing consumption. This increase in hours, in turn, gives a boost to output on impact. The overall expansionary effect on output will be higher, the higher the degree of price rigidities.

As already observed in the case of technology shock, with a cap-and-trade the expansionary effects are less pronounced, since respecting the cap absorbs more resources for emissions abatement.

Turning to the response of the environment-related variables, we observe emissions showing similar patterns across regimes, while abatement and permit price differ across regimes. In fact the increase in public spending induces a rise in output which translates into higher emissions in all regimes, with the exception of the emissions cap, where, as seen before, the expansionary policy entails a greater abatement effort and a boost in the permit price. Further, as already emphasized, under a tax policy emissions behave exactly as in the no policy scenario, being constant the abatement effort. Overall, when comparing these results with those obtained in response to a technology shock, we observe qualitatively distinct responses of variables such as consumption and investment, while the responses of the emissions related variables are qualitatively very similar. Both shocks, in fact, generate a positive temporary effect on output, and so on emissions and abatement effort. 


\subsection{Monetary Policy Shock}

Figure 3 displays the impulse responses of the main macroeconomic variables to a monetary policy shock. More specifically, we consider an increase of $0.25 \%$ in the innovation $\eta_{t}$. In this example, to abstract from the endogenous changes in the nominal interest rate induced by the response to inflation, we set $\iota_{\pi}=0$.

This policy shock generates an increase in the real interest rate, which in turn, depresses aggregate demand and so output. Output and labor, in fact, sharply decline in response to the tightening of monetary policy, following the contraction in consumption and investment resulting from the nominal interest rate hike. However, already in the second period, the economy recovers since the persistently higher real interest rate depresses consumption and favors capital accumulation, so that output expands. In the case of cap-and-trade, since emission abatement is a costly activity, firms will find it optimal to reduce their abatement effort in response to the contractionary shock, so that aggregate emissions stay at the cap level.

Under an intensity target policy, emissions fall, while abatement and permit price hike on impact. Intuitively, since only a small fraction of firms are in the position of resetting their prices in response to the changed economic conditions, we observe that the abatement effort and the permit price initially increase. Firms resetting their prices, in fact, face a lower demand reduction than that faced by those firms whose prices are stuck at their previous period values. This implies that re-optimizing producers reduce less their output and the abatement effort rises, so that the intensity target constraint is fully met at aggregate level. Finally, in the tax policy scenario the abatement effort of producers is constant, implying a reduction in emissions that is proportional to output.

\subsection{Moments}

To better understand the dynamic behavior of the economy under different environmental policy regimes we compute the theoretical moments of the main macrovariables produced by the model. Since starting from a solution at second-order approximation, there is no closedform solution for unconditional moments, we report a second order approximation of these 
moments. $^{27}$

In order to further assess the implications of price rigidities we consider three different degrees of nominal rigidities: (i) $\xi=3 / 4$ (benchmark level), (ii) $\xi=0$ (flexible prices), (iii) $\xi=4 / 5$ (high degree of nominal rigidities). Table 3 gives the theoretical means of the main macrovariables. Table 4 reports the standard deviations of the main macrovariables (first column), also expressed in relative terms with respect to output (second column), while Table 5 presents the correlations with output. Finally, Table 6 reports mean and standard deviation of the welfare. The main findings of our analysis can be summarized as follows.

From Table 3 we notice that as long as prices are fully flexible the intensity target and the tax policy regimes behave in the same way, although results for the cap-and-trade are only negligibly different. The differences across environmental regimes arise when nominal rigidities come into play, although the differences are negligible for $\xi=3 / 4$, while for higher degree of nominal rigidities (i.e. $\xi=4 / 5$ ) the means of output and emissions are slightly higher with an intensity target than with a cap-and-trade or a tax. Moreover, we notice that with a high degree of nominal rigidities marginal costs differ across regimes. As expected, the cap-andtrade regime shows the highest marginal cost, reflecting the greater relative effort in abating emissions necessary to respect the cap.

Now consider Table 4. First, as expected, the volatility of the economy tends to be higher, the higher the degree of nominal rigidities. Also the variables pertaining to the environment and the emissions control are more volatile when the probability that prices will stay unchanged is high. Intuitively, when prices cannot adjust, or can only adjust slowly, output is demand determined and becomes more volatile, driving all the other real variables of the economy. Under flexible prices, instead, price changes mitigate the effects of real shocks and neutralize the effects of monetary policy shocks, and markups will be at the desired level (i.e. real marginal costs stay constant).

Second, under the intensity-target emission-control policy, when prices are fully flexible, the economy behaves as under a tax policy regime, because of the lack of any source of heterogeneity across price-setting firms induced by nominal rigidities. On the other hand, for very rigid prices

\footnotetext{
${ }^{27}$ The computer package Dynare we use to find the solution of the model calculates theoretical moments for all the endogenous variables using the approximation method of Kim et al. (2008).
} 
the differences between the two regimes are remarkably higher and the economy becomes more volatile under an intensity target regime.

Third, under a cap-and-trade policy and fully flexible prices, standard deviations of output, consumption, investment and labor are lower, while those of marginal cost, permit price and abatement effort are higher than under the other emission control policies. As already remarked, the cap-and-trade imposes an immediate adjustment of the abatement effort when the economy faces a shock. This extra cost, in turn, limits the reactivity of output to shock, while making marginal costs more responsive and permit prices more volatile.

It is worth noticing that when nominal rigidities are high (i.e. $\xi=4 / 5$ ) also the volatilities of marginal costs, of abatement effort and of permit prices are lower with a cap-and-trade than with an intensity target.

Finally, with regards to the relative standard deviations, we notice that the relative variability of consumption with respect to output decreases when prices become stickier, while for labor and investments we observe the opposite. For a cap-and-trade regime the relative variability of abatement effort and permit prices tends to increase when prices are more flexible.

We now move to correlations with output displayed in Table 5. We observe that the correlation of labor, investments and marginal costs tends to be higher, the higher the degree of nominal rigidities. This is because under slow price adjustment firms are forced to change their factor inputs to absorb the shocks. Also we notice that labor becomes slightly countercyclical when prices are flexible and the environmental policy is set according to a cap-and-trade.

Moreover, we observe that with fully flexible prices the abatement effort is perfectly procyclical under a cap-and-trade. Emissions move perfectly procyclically under tax policy and intensity target regimes. Under intensity targets permit prices and abatement effort are countercyclical. Obviously under this regime, when output is higher, emissions can increase proportionally requiring a lower abatement effort and inducing a drop of permit prices.

Finally, Table 6 reports mean welfare expressed as a percentage of the no policy case and the standard deviation. We observe that under fully flexible prices the higher level of welfare on average is achieved with an intensity target and with a tax, but at a cost of higher volatility. As already emphasized, in fact, with a cap-and-trade the economy is more stabilized. In the 
benchmark case, with an emission intensity target, mean welfare is slightly lower than with a tax, but still slightly higher that with a cap-and-trade, recording a higher standard deviation. On the contrary, when prices are very rigid, mean welfare is found to be higher under a capand-trade.

It should be noted that the positive performance of the intensity target under flexible price is consistent with the results obtained by Fischer and Springborn (2011) in a RBC model, despite the different way in which emissions are modelled. In addition, our analysis confirms that a cap-and-trade policy yields the lowest volatility of all economic variables, with the exception of the permit prices and the abatement effort. ${ }^{28}$ We complement their results by showing that the stabilizing ability of a cap-and-trade policy is particularly strong in the presence of nominal rigidities. These stabilizing properties of the cap-and-trade, in turn, would produce minor mean welfare loss when prices are very sticky, while the differences with the other regimes become negligible under flexible prices. Intuitively, nominal rigidities increase the overall uncertainty of the economy, that is why a regulation that forces a smoothing response of real variables tends to be preferred. This finding is consistent with the result of Kelly (2005), who shows that in a general equilibrium framework the presence of uncertainty may lead to prefer quantity regulation to price regulation for a reasonable degree of risk aversion.

Further, it can be shown that the interplay between adjustment costs on capital and nominal rigidities plays an important role in shaping the performance of the different policies, with the cap-and-trade performing particularly better in the presence of a high degree of both frictions, while the differences across regimes tend to diminish for lower capital adjustment costs. ${ }^{29}$ Intuitively, high price stickiness on the production side constrains the capacity of the economy to adjust and volatility of real variables rises and so the adjustment costs on capital. By anchoring the economy to a given level of emissions, a cap-and-trade policy mitigates the effects on real variables and reduces the adjustment costs.

Overall, our analysis confirms that for a high degree of nominal rigidities the type of the environmental policy regime put in place is able to affect significantly the dynamics and the

\footnotetext{
${ }^{28}$ These two results are also found when shutting down all the other frictions of the model, namely the adjustment costs on capital, imperfect competition and monetary policy. These additional findings are available from the authors upon request.

${ }^{29}$ These additional results are also available from the authors upon request.
} 
volatility of the economy.

\section{Ramsey Environmental Policy}

In this Section we complete our analysis by looking at the optimal environmental policy in response to shocks for different degrees of price rigidities and for different monetary policy conducts. In particular, we focus on the Ramsey optimal policy where a benevolent government (Ramsey planner) maximizes the expected discounted utility of households, given the constraints of the decentralized economy. We consider the case of a Ramsey planner controlling optimally the tax rate on emissions. It can be shown that the same allocation can be obtained by a planner controlling the quantity of pollutant emissions or their intensity with respect to output. ${ }^{30}$ As a common practice, we assume that the government is able to commit to the contingent policy rule it announces at time 0 (i.e. ex-ante commitment to a feedback policy, so as to have the ability to dynamically adapt the policy to the changed economic conditions).

In what follows we first consider the case of a Ramsey planner choosing environmental regulation for different levels of nominal rigidities and, taking as given monetary policy which is, in turn, conducted according to rule (21). ${ }^{31}$ Then, as an interesting benchmark, we consider the case of a Ramsey planner choosing both environmental and monetary policy instruments and we compare the results with those obtained when the nominal interest rate is set according to (21), for different values of the policy parameter $\iota_{\pi}$. In both cases we start from the optimality conditions for households and firms and then reduce the number of constraints to the Ramsey planner's optimal problem by substitution. The dynamic responses of the Ramsey plans are computed by taking second order approximations of the set of first order conditions around the steady state using the baseline calibration presented in Section 3. The Ramsey problem is fully described in the Appendix, while in this Section we focus on the dynamic response of the optimal emissions tax in response to shocks.

\footnotetext{
${ }^{30}$ See the Appendix. As pointed out by Heutel (2012) this equivalence holds when the policy maker has symmetric information about all state variables of the economy.

${ }^{31}$ The assumption of separating the conduct of environmental and monetary policy also in this normative analysis is motivated by the fact that in many advanced and emerging countries monetary policy is conducted by independent central banks with the explicit mandate to achieve specific goals in terms of inflation and/or economic activity.
} 
It should be mentioned that by solving the Ramsey problem in the deterministic steady state one can find the optimal level of environmental tax in the absence of shocks, which is found to be positive although very close to zero, given the small dimension of the negative externality that the stock of pollutant exerts on production possibility at the baseline calibration. However, it can be shown that by moving toward an equilibrium characterized by more competition, the level of economic activity increases sharply, and so emissions flows and pollutant stock, along with the negative externality on productivity. As a result, the optimal level of taxation on emissions is shown to increase sharply. ${ }^{32}$

Figure 4 shows the Ramsey optimal impulse response functions of emissions tax and of emissions for different levels of nominal rigidities $(\xi=3 / 4$ continuous lines, $\xi=0$ dotted lines, $\xi=4 / 5$ dashed lines) under the assumption that the Ramsey planner sets only environmental regulation, taking as given monetary policy which instead obeys to $(21)$ with $\iota_{\Pi}=3$, as in the previous analysis.

The first row presents the response to an increase in productivity $A_{t}$, which has a positive impact on output. Consistently with the results of Heutel (2012) and Angelopoulos et al. (2013), we show that the optimal emissions tax is procyclical, being so able to mitigate the increase of emissions due to the expansion of output. Without this positive reaction of the emissions tax, in fact, emissions would be more procyclical than under the Ramsey allocation. However, here we further show that the optimal response of emissions tax tends to be more intense, the higher the degree of nominal rigidities. As already stressed, the distortions created by the imperfect price adjustment render the decentralized allocation less efficient (i.e. because of the price dispersion and the high volatility of real variables), requiring a stronger reaction of the optimal emissions tax in response to shocks.

The second row shows the response to an increase in public consumption that creates an output expansion through higher aggregate demand. Emissions increase as expected, while optimal tax falls on impact and then increases. This is due to the fact that, as already noticed in Section 4, an increase in public spending crowds out consumption and investment, also through the operation of the interest rate rule, according to which the nominal interest rate

\footnotetext{
${ }^{32}$ See the Appendix.
} 
aggressively reacts to inflation. The Ramsey planner will find it optimal to partially offset this effect by temporarily reducing the tax rate on emissions. However, since under flexible prices the crowding out effect of private expenditure is particularly strong, we observe that optimal emissions tax tends to be lower than its steady state level for all the adjustment time horizon.

Finally, the third row shows the response to a positive shock on the nominal interest rate, which translates into a contractionary effect on output and so on emissions. In this case the optimal emissions tax is again fully procyclical. The Ramsey planner tends to offset the contractionary effect on output by temporarily reducing the tax on emissions. As expected, this reaction is stronger the higher the level of nominal rigidities, since under these circumstances the effects of a monetary policy shocks are more pronounced.

We now move to the analysis of the optimal environmental policy, given different monetary regimes. See Figure 5. As already explained, we use as a benchmark the case of a benevolent Ramsey planner able to set optimality emissions tax and the nominal interest rate (continuous lines) and we compare the dynamic responses so obtained to those computed in the case of a monetary policy conducted according to a simple rule for $\iota_{\Pi}=1.2$ (dotted lines) and $\iota_{\Pi}=3$ (dashed lines). Also in the case of optimal monetary policy the optimal response tends to be procyclical in response to a technology shock, but is less reactive than when the monetary policy follows a simple rule. In particular, a weak reaction to inflation of the monetary authority (i.e. $\iota_{\Pi}=1.2$ ) requires a stronger response of the optimal tax. Intuitively, as a result of a weak commitment to price stability of the monetary authority and of the related diminished ability to reduce the distortions created by imperfect price adjustment, the Ramsey planner is called to compensate this deficiency by choosing a more procyclical tax policy. A similar mechanism is observed in the case of a public consumption shock, where for a non optimal reactivity of the nominal interest rate to the positive shock on public consumption, the Ramsey planner will find it optimal to react more to the changed economic conditions by reducing the emissions tax on impact and increasing it later (especially for $\iota_{\Pi}=1.2$ )

Finally, we show the response of the emissions tax to a positive temporary increase in the nominal interest rate and we observe again that the reactivity of the optimal emissions tax is more pronounced the weaker the offsetting response of the feedback rule. Notice that 
when instead the Ramsey planner also controls the nominal interest rate, the shock will be immediately absorbed and all the possible effects on the economy will be neutralized.

\section{Conclusion}

We present a NK dynamic general equilibrium model embodying pollutant emissions and environmental policy. We analyze the performance of alternative environmental policy rules under real and nominal uncertainty and find the optimal policy response to inflation. Our results are as follows. First, a cap-and-trade policy acts as an automatic stabilizer of the economy, since emission permit prices and firms' abatement effort are procyclical, so dampening business cycle fluctuations. Second, stickiness in prices plays a major role in shaping the effects of emissions regulation. In particular, an emissions intensity target regime is likely to generate more macroeconomic volatility when the degree of price rigidities is high. Third, welfare is less volatile under a cap-and-trade, as expected, while its mean value tends to be slightly higher with a tax policy, provided that the degree of price rigidity is not too high, otherwise mean welfare tends to be higher under a cap-and-trade policy. For a high degree of nominal rigidities the adoption of an emissions intensity target policy yields a lower level of welfare than that observed under a tax or a cap-and-trade regime. Finally, the Ramsey environmental tax response to shocks is shown to crucially depend on the magnitude of price rigidities and on the monetary policy conduct. In particular, the optimal policy response of taxation is found to be stronger when prices are stickier and the monetary authority weakly reacts to inflation deviation from its target level. On the contrary, a milder optimal reaction to shocks is found under fully flexible prices or when the Ramsey planner is also able to set monetary policy optimally.

The present model is based deliberately on a number of simplifying assumptions in order to stress the intuition behind the influence of environmental policy on the transmission mechanism of some common shocks considered in the literature. We argue that the insights obtained here prepare the ground for more complex explorations on the relationship between business cycle and environmental policy. An important direction for future research might be to incorporate additional shocks into the analysis, since ideally these kinds of investigations should incorporate into the model all of the sources of uncertainty that are important drivers of economic 
fluctuations. Other relevant sources of frictions and rigidities, such as labor market frictions in the form of wage rigidities and labor adjustment cost, which are known to affect considerably the business cycle and therefore the policy prescriptions, should be introduced into the model. Along this line of research, many other features could be included in the present model, such as distortionary taxation on labor income, consumption and capital, opening up to a non-trivial interaction between environmental regulations and fiscal stabilization policies. Furthermore, the issue of the interaction between environmental and monetary policy has been touched upon in this paper, but deserves much further research. Clearly, the changes in the nominal interest rates induced by a central bank in response to shocks are able to set in motion a number of mechanisms and actions by economic agents and ultimately influence the developments of output and emissions. Finally, the analysis conducted in this paper allows us only to explore the implications of environmental regulations and provide policy prescriptions for an economy that have reached its steady-state level. However, since environmental policy regarding climate change focuses on long-term goals, more work should be devoted to the study of the transition of the economy toward a low-carbon new steady state, starting from a no policy equilibrium, accounting for uncertainty and comparing the performance of the different policy options along the adjustment path.

\section{References}

Adjemian, S., Bastani, H., Juillard, M., Mihoubi, F.,Perendia, G., Ratto, M., Villemot, S., (2011). Dynare: Reference Manual, Version 4, Dynare Working Papers no. 1, CREPEMAQ.

Álvarez, L.J., Dhyne, E., Hoeberichts, M., Kwapil, C., Le Bihan, H., Lünnemann, P., Martins, F., Sabbatini, R., Stahl, H., Vermeulen, P., Vilmunen, J., (2006). Sticky Prices in the Euro Area: A Summary of New Micro-Evidence, Journal of the European Economic Association, 4, 575-584.

Angelopoulos, K., Economides, G., Philippopoulos, A., (2010). What is the Best Environmental Policy? Taxes, Permits and Rules under Economic and Environmental Uncertainty, CESifo Working Paper Series 2980, CESifo Group Munich.

Angelopoulos, K., Economides, G., Philippopoulos, A., (2013) First-and Second-Best Allocations under Economic and Environmental Uncertainty, International Tax and Public Finance, $20,360-380$. 
Bartz, S., Kelly, D. L., (2008). Economic Growth and the Environment: Theory and Facts, Resource and Energy Economics, 30, 115-149.

Bils, M., Klenow, P.J., (2004). Some Evidence on the Importance of Sticky Prices, Journal of Political Economy, 112, 947-985.

Bouman, M., Gautier, P.A., Hofkes, M.W., (2000). Do Firms Time Their Pollution Abatement Investments Optimally? De Economist, 148, 71-86.

Calvo, G., (1983). Staggered Prices in a Utility-Maximizing Framework, Journal of Monetary Economics, 12, 383-398.

Clarida, R., Galí, J., Gertler, M., (1999). The Science of Monetary Policy: A New Keynesian Perspective, Journal of Economic Literature, 37, 1661-1707.

Dhyne, E., Alvarez, L.J., Le Bihan, H., Veronese, G., Dias, D., Hoffmann, J., Jonker, N., Lunnemann, P., Rumler, F., Vilmunen, J., (2006). Price Changes in the Euro Area and the United States: Some Facts from Individual Consumer Price Data, Journal of Economic Perspectives, 20, 171-192.

Dissou, Y., (2005). Cost-Effectiveness of the Performance Standard System to Reduce CO2 Emissions in Canada: A General Equilibrium Analysis, Resource and Energy Economics, 27, $187-207$.

Fischer, C., Heutel, G., (2013). Environmental Macroeconomics: Environmental Policy, Business Cycles, and Directed Technical Change, Annual Review of Resource Economics, 5, 197-210.

Fischer, C., Springborn, M., (2011). Emissions Targets and the Real Business Cycle: Intensity Targets versus Caps or Taxes, Journal of Environmental Economics and Management, $62,352-366$.

Galí, J., (2008). Monetary Policy, Inflation, and the Business Cycle, Princeton and Oxford: Princeton University Press.

Goulder, L.H., Parry, I.W.H., Williams III, R.C., Burtraw, D., (1999). The Cost-Effectiveness of Alternative Instruments for Environmental Protection in a Second-Best Setting, Journal of Public Economics 72, 329-360.

Heutel, G., (2012). How Should Environmental Policy Respond to Business Cycles? Optimal Policy under Persistent Productivity Shocks, Review of Economic Dynamics, 15, 244-264.

Hoel, M., Karp, L., (2002). Taxes versus Quotas for a Stock Pollutant, Resource and Energy Economics, 24, 367-384.

Kelly, D. L., (2003). On Environmental Kuznets Curves Arising from Stock Externalities, Journal of Economic Dynamics and Control, 27, 1367-1390.

Kelly, D. L., (2005). Price and Quantity Regulation in General Equilibrium, Journal of Economic Theory, 125, 36-60.

Kim, J., Kim, S. Schaumburg, E., Sims, C.A. (2008). Calculating and Using SecondOrder Accurate Solutions of Discrete Time Dynamic Equilibrium Models, Journal of Economic Dynamics and Control, 32(11), 3397-3414. 
Klenow, P., Malin, B., (2011). Microeconomic evidence on price-setting, in B. Friedman, M. Woodford (Eds.), Handbook of Monetary Economics, Elsevier, Amsterdam, 231-284.

Jotzo, F., Pezzey, J.C.V., (2007). Optimal Intensity Targets for Greenhouse Gas Emissions Trading under Uncertainty, Environmental and Resource Economics, 83, 280-286.

Judd, K., (1998). Numerical Methods in Economics, Cambridge MA: MIT Press.

Newell, R.G., Pizer, W.A. (2008). Indexed Regulation, Working Paper 13991, National Bureau of Economic Research, Cambridge, MA.

Nordhaus, W.D., (2008). A Question of Balance: Weighing the Options on Global Warming Policies. New Haven and London: Yale University Press.

Parry, I.W.H.,Williams III, R.C., (1999). Second-Best Evaluation of Eight Policy Instruments to Reduce Carbon Emissions, Resource and Energy Economics, 21, 347-373.

Pizer, W.A. (2005). The Case for Intensity Targets, Climate Policy, 5, 455-462

Pizer, W. A., Kopp, R., (2005). Calculating the Costs of Environmental Regulation, in K. G. Mäler \& J. R. Vincent (ed.), Handbook of Environmental Economics, edition 1, volume 3, chapter 25, 1307-1351.

Quirion, P., (2005). Does Uncertainty Justify Intensity Emission Caps? Resource and Energy Economics, 27, 343-353.

Schmitt-Grohé, S., Uribe, M., (2004). Solving Dynamic General Equilibrium Models Using a Second-Order Approximation to the Policy Function, Journal of Economic Dynamics and Control, 28, 755-775.

Schmitt-Grohé, S., Uribe, M., (2007). Optimal, Simple, and Implementable Monetary and Fiscal Rules, Journal of Monetary Economics, 54, 1702-1725.

Smets, F., Wouters, R., (2007). Shocks and Frictions in US Business Cycles: A Bayesian DSGE Approach, American Economic Review, 97, 586-606.

Stern, N., (2008). The Economics of Climate Change, American Economic Review, 98, 1-37.

Weitzman, M.L. (1974). Prices vs. Quantities, Review of Economic Studies, 41, 477-491.

Woodford, M., (2003). Interest and Prices: Foundations of a Theory of Monetary Policy, Princeton and Oxford: Princeton University Press. 
Table 1: Parametrization

\begin{tabular}{l|l|l}
\hline \hline Parameters & Value & Description \\
\hline$\alpha$ & $1 / 3$ & Technology parameter \\
$\delta_{K}$ & 0.99 & Discount factor \\
$\gamma_{I}$ & 0.025 & Depreciation rate of capital \\
$\phi$ & 15 & Capital adjustment cost \\
$\theta$ & 6 & Inverse of the Frisch elasticity of labor supply \\
$\xi$ & $3 / 4$ & Price elasticity \\
$A$ & 1.2480 & Calvo's price parameter for nominal rigidities \\
$\mu_{L}$ & 19.8413 & Total factor productivity \\
$\iota_{\pi}$ & 3 & Disutility of labor \\
$1-\delta_{M}$ & 0.9979 & Interest rate rule parameter \\
$\varphi$ & 0.45 & Pollution decay \\
$\phi_{1}$ & 0.1850 & Emissions per unit of output \\
$\phi_{2}$ & 2.8 & Abatement cost function coefficient \\
$\gamma_{0}$ & $1.3950 e-3$ & Abatement cost function parameter \\
$\gamma_{1}$ & $-6.6722 e-6$ & Parameter of the damage function \\
$\gamma_{2}$ & $1.4647 e-8$ & Parameter of the damage function \\
$\sigma_{A}$ & 0.0045 & Standard deviation of productivity shock \\
$\sigma_{G}$ & 0.0053 & Standard deviation of public consumption shock \\
$\sigma_{\eta}$ & 0.0024 & Standard deviation of monetary shock \\
$\rho_{A}$ & 0.95 & Persistence of productivity shock \\
$\rho_{G}$ & 0.97 & Persistence of public consumption shock \\
$\rho_{\eta}$ & 0.15 & Persistence of monetary shock \\
\hline \hline
\end{tabular}


Table 2: Deterministic Steady State, Percentage Changes Relative to the No-Policy Case and Welfare Costs

\begin{tabular}{l|r|r}
\hline \hline & No-Policy & Environmental Policy \\
\hline$Y$ & 0.7780 & $0.7592(-2.4182 \%)$ \\
$C$ & 0.5446 & $0.5321(-2.3041 \%)$ \\
$I$ & 0.1539 & $0.1465(-4.7911 \%)$ \\
$L$ & 0.2 & $0.1974(-1.2877 \%)$ \\
$M C$ & 0.8333 & $0.8333(0 \%)$ \\
$Z$ & 0.3501 & $0.2801(-20 \%)$ \\
$M$ & 800 & $766.6558(-4.1680 \%)$ \\
$U$ & 0 & 0.1801 \\
$p_{Z}$ & 0 & 0.0512 \\
$\mathcal{C}_{A} / Y$ & 0 & 0.0015 \\
$\Gamma(M)$ & $0.5431 \%$ & $0.4889 \%(-0.0542 \mathrm{p} . \mathrm{p})$. \\
$W e l$ fare & -100.4489 & $-101.7685(-1.3136 \%)$ \\
Welfare Cost & 0 & $1.3109 \%$ \\
\hline \hline
\end{tabular}


Table 3: Means

\begin{tabular}{|c|c|c|c|c|c|}
\hline & & No Policy & Cap-and-Trade & Intensity Target & $\operatorname{Tax}$ \\
\hline \multirow{10}{*}{$\xi=3 / 4$} & $Y$ & 0.7781 & 0.7592 & 0.7593 & 0.7593 \\
\hline & $C$ & 0.5446 & 0.5320 & 0.5321 & 0.5321 \\
\hline & $I$ & 0.1540 & 0.1465 & 0.1466 & 0.1466 \\
\hline & $L$ & 0.2000 & 0.1974 & 0.1974 & 0.1974 \\
\hline & $M C$ & 0.8331 & 0.8331 & 0.8330 & 0.8331 \\
\hline & $Z$ & 0.3501 & 0.2801 & 0.2801 & 0.2801 \\
\hline & $M$ & 800.0115 & 766.6558 & 766.6686 & 766.6629 \\
\hline & $U$ & & 0.1797 & 0.1802 & 0.1801 \\
\hline & $p_{Z}$ & & 0.0514 & 0.0513 & 0.0512 \\
\hline & $\mathcal{C}_{A}$ & & 0.0012 & 0.0011 & 0.0011 \\
\hline \multirow{10}{*}{$\xi=0$} & $Y$ & 0.7782 & 0.7593 & 0.7594 & 0.7594 \\
\hline & $C$ & 0.5447 & 0.5321 & 0.5322 & 0.5322 \\
\hline & $I$ & 0.1540 & 0.1465 & 0.1466 & 0.1466 \\
\hline & $L$ & 0.2000 & 0.1974 & 0.1974 & 0.1974 \\
\hline & $M C$ & 0.8333 & 0.8333 & 0.8333 & 0.8333 \\
\hline & $Z$ & 0.3502 & 0.2801 & 0.2802 & 0.2802 \\
\hline & $M$ & 800.0385 & 766.6558 & 766.6866 & 766.6866 \\
\hline & $U$ & & 0.1799 & 0.1801 & 0.1801 \\
\hline & $p_{Z}$ & & 0.0514 & 0.0512 & 0.0512 \\
\hline & $\mathcal{C}_{A}$ & & 0.0011 & 0.0011 & 0.0011 \\
\hline \multirow{10}{*}{$\xi=4 / 5$} & $Y$ & 0.7772 & 0.7586 & 0.7594 & 0.7581 \\
\hline & $C$ & 0.5435 & 0.5313 & 0.5295 & 0.5297 \\
\hline & $I$ & 0.1541 & 0.1465 & 0.1487 & 0.1474 \\
\hline & $L$ & 0.1993 & 0.1971 & 0.1942 & 0.1954 \\
\hline & $M C$ & 0.8275 & 0.8307 & 0.8067 & 0.8166 \\
\hline & $Z$ & 0.3491 & 0.2801 & 0.2802 & 0.2778 \\
\hline & $M$ & 799.5048 & 766.6558 & 766.6855 & 765.5492 \\
\hline & $U$ & & 0.1774 & 0.1755 & 0.1801 \\
\hline & $p_{Z}$ & & 0.0513 & 0.0504 & 0.0512 \\
\hline & $\mathcal{C}_{A}$ & & 0.0012 & 0.0011 & 0.0011 \\
\hline
\end{tabular}


Table 4: Standard Deviations

\begin{tabular}{|c|c|c|c|c|c|c|c|c|c|}
\hline & & \multicolumn{2}{|c|}{ No Policy } & \multicolumn{2}{|c|}{ Cap-and-Trade } & \multicolumn{2}{|c|}{ Intensity Target } & \multicolumn{2}{|c|}{ Tax } \\
\hline & & $\sigma(X)$ & $\frac{\sigma(X)}{\sigma(Y)}$ & $\sigma(X)$ & $\frac{\sigma(X)}{\sigma(Y)}$ & $\sigma(X)$ & $\frac{\sigma(X)}{\sigma(Y)}$ & $\sigma(X)$ & $\frac{\sigma(X)}{\sigma(Y)}$ \\
\hline \multirow{10}{*}{$\xi=3 / 4$} & $Y$ & 0.0228 & 1 & 0.0199 & 1 & 0.0233 & 1 & 0.0226 & 1 \\
\hline & $C$ & 0.0106 & 0.4660 & 0.0092 & 0.4619 & 0.0105 & 0.4490 & 0.0104 & 0.4610 \\
\hline & $I$ & 0.0162 & 0.7130 & 0.0140 & 0.7036 & 0.0171 & 0.7360 & 0.0163 & 0.7191 \\
\hline & $L$ & 0.0040 & 0.1769 & 0.0035 & 0.1781 & 0.0045 & 0.1916 & 0.0042 & 0.1843 \\
\hline & $M C$ & 0.0186 & 0.8197 & 0.0178 & 0.8965 & 0.0198 & 0.8507 & 0.0193 & 0.8511 \\
\hline & $Z$ & 0.0088 & 0.3886 & 0 & 0 & 0.0086 & 0.3689 & 0.0072 & 0.3166 \\
\hline & M & 0.8429 & 37.0495 & 0 & 0 & 0.6759 & 29.0321 & 0.6757 & 29.8354 \\
\hline & $U$ & & & 0.0183 & 0.9181 & 0.0065 & 0.2776 & 0 & 0 \\
\hline & $p_{Z}$ & & & 0.0093 & 0.46977 & 0.0033 & 0.14203 & 0 & 0 \\
\hline & $\mathcal{C}_{A}$ & & & 0.0003 & 0.0173 & 0.0001 & 0.0044 & 0.0000 & 0.0013 \\
\hline \multirow{10}{*}{$\xi=0$} & $Y$ & 0.0170 & 1 & 0.0145 & 1 & 0.0166 & 1 & 0.0166 & 1 \\
\hline & $C$ & 0.0105 & 0.6179 & 0.0091 & 0.6257 & 0.0103 & 0.6232 & 0.0103 & 0.6232 \\
\hline & $I$ & 0.0080 & 0.4722 & 0.0063 & 0.4360 & 0.0077 & 0.4645 & 0.0077 & 0.4645 \\
\hline & $L$ & 0.0008 & 0.0474 & 0.0006 & 0.0404 & 0.0008 & 0.0473 & 0.0008 & 0.0473 \\
\hline & $M C$ & 0 & 0 & 0 & 0 & 0 & 0 & 0 & 0 \\
\hline & $Z$ & 0.0076 & 0.4500 & 0 & 0 & 0.0061 & 0.3689 & 0.0061 & 0.3689 \\
\hline & $M$ & 0.8429 & 49.6574 & 0 & 0 & 0.6756 & 40.7920 & 0.6756 & 40.7920 \\
\hline & $U$ & & & 0.0157 & 1.0799 & 0 & 0 & 0 & 0 \\
\hline & $p_{Z}$ & & & 0.0080 & 0.5526 & 0 & 0 & 0 & 0 \\
\hline & $\mathcal{C}_{A}$ & & & 0.0003 & 0.0204 & 0.0000 & 0.0015 & 0.0000 & 0.0015 \\
\hline \multirow{10}{*}{$\xi=4 / 5$} & $Y$ & 0.0672 & 1 & 0.0438 & 1 & 0.1424 & 1 & 0.1113 & 1 \\
\hline & $C$ & 0.0114 & 0.1699 & 0.0096 & 0.2187 & 0.0138 & 0.0970 & 0.0126 & 0.1133 \\
\hline & $I$ & 0.0614 & 0.9137 & 0.0386 & 0.8798 & 0.1332 & 0.9353 & 0.1032 & 0.9276 \\
\hline & $L$ & 0.0195 & 0.2895 & 0.0123 & 0.2809 & 0.0431 & 0.3025 & 0.0335 & 0.3008 \\
\hline & $M C$ & 0.0992 & 1.4757 & 0.0678 & 1.5472 & 0.2104 & 1.4777 & 0.1688 & 1.5168 \\
\hline & $Z$ & 0.0234 & 0.3477 & 0 & 0 & 0.0525 & 0.3689 & 0.0314 & 0.2822 \\
\hline & M & 0.8446 & 12.5622 & 0 & 0 & 0.6789 & 4.7668 & 0.6778 & 6.0921 \\
\hline & $U$ & & & 0.0366 & 0.8355 & 0.0375 & 0.2623 & 0 & 0 \\
\hline & $p_{Z}$ & & & 0.0187 & 0.4275 & 0.0192 & 0.1346 & 0 & 0 \\
\hline & $\mathcal{C}_{A}$ & & & 0.0007 & 0.0157 & 0.0005 & 0.00353 & 0.0001 & 0.0011 \\
\hline
\end{tabular}


Table 5: Correlations with Output

\begin{tabular}{|c|c|c|c|c|c|}
\hline & & No Policy & "Cap-and-Trade & Intensity Target & $\bar{T}$ Tax \\
\hline \multirow{10}{*}{$\xi=3 / 4$} & $Y$ & 1.00 & 1.00 & 1.00 & 1.00 \\
\hline & $C$ & 0.76 & 0.75 & 0.73 & 0.75 \\
\hline & $I$ & 0.91 & 0.90 & 0.91 & 0.91 \\
\hline & $L$ & 0.71 & 0.64 & 0.73 & 0.72 \\
\hline & $M C$ & 0.62 & 0.63 & 0.65 & 0.64 \\
\hline & $Z$ & 0.97 & & 1.00 & 0.97 \\
\hline & $M$ & 0.18 & & 0.17 & 0.18 \\
\hline & $U$ & & 0.97 & -0.66 & \\
\hline & $p_{Z}$ & & 0.97 & -0.66 & \\
\hline & $\mathcal{C}_{A}$ & & 0.97 & -0.45 & 0.97 \\
\hline \multirow{10}{*}{$\xi=0$} & $Y$ & 1.00 & 1.00 & 1.00 & 1.00 \\
\hline & $C$ & 0.93 & 0.94 & 0.93 & 0.93 \\
\hline & $I$ & 0.89 & 0.89 & 0.89 & 0.89 \\
\hline & $L$ & 0.48 & -0.09 & 0.47 & 0.47 \\
\hline & $M C$ & & & & \\
\hline & $Z$ & 1.00 & & 1.00 & 1.00 \\
\hline & $M$ & 0.24 & & 0.24 & 0.24 \\
\hline & $U$ & & 1.00 & & \\
\hline & $p_{Z}$ & & 1.00 & & \\
\hline & $\mathcal{C}_{A}$ & & 1.00 & 1.00 & 1.00 \\
\hline \multirow{10}{*}{$\xi=4 / 5$} & $Y$ & 1.00 & 1.00 & 1.00 & 1.00 \\
\hline & $C$ & 0.57 & 0.56 & 0.73 & 0.66 \\
\hline & $I$ & 0.99 & 0.98 & 1.00 & 1.00 \\
\hline & $L$ & 0.96 & 0.93 & 0.99 & 0.99 \\
\hline & $M C$ & 0.95 & 0.92 & 0.99 & 0.98 \\
\hline & $Z$ & 0.99 & & 1.00 & 1.00 \\
\hline & $M$ & 0.07 & & 0.07 & 0.06 \\
\hline & $U$ & & 0.99 & -0.98 & \\
\hline & $p_{Z}$ & & 0.99 & -0.98 & \\
\hline & $\mathcal{C}_{A}$ & & 0.99 & -0.96 & 1.00 \\
\hline
\end{tabular}


Table 6: Welfare Mean and Standard Deviations

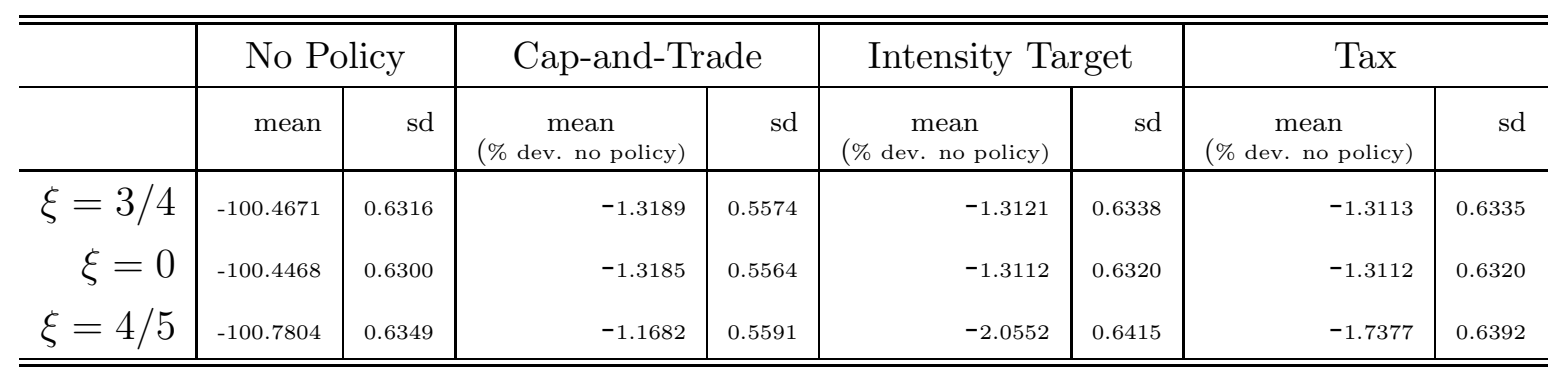


Figure 1: Impulse Responses to a Technology Shock
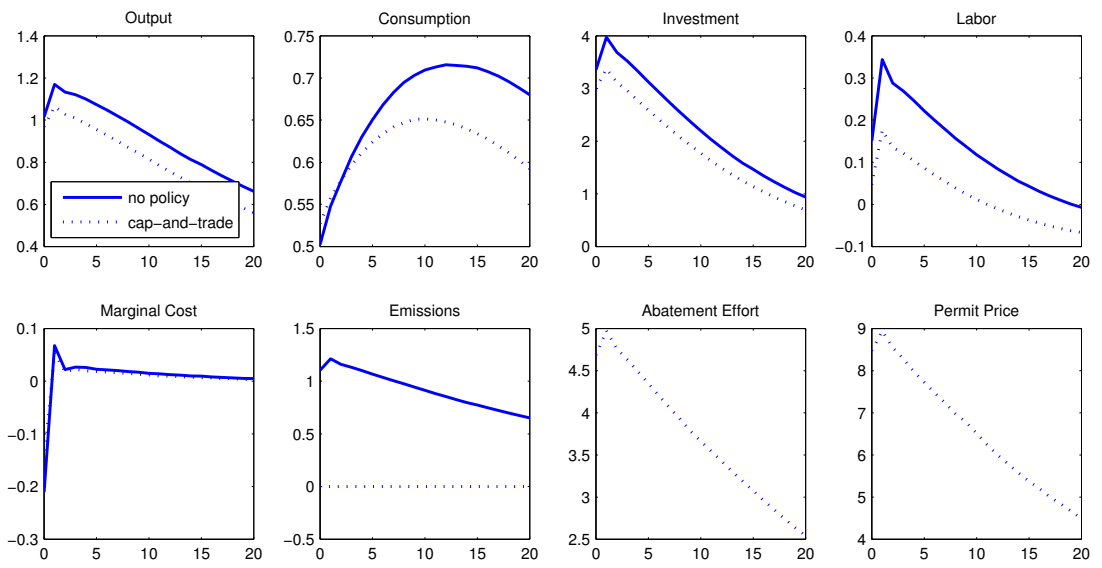

(a) No Policy and Cap-and-Trade
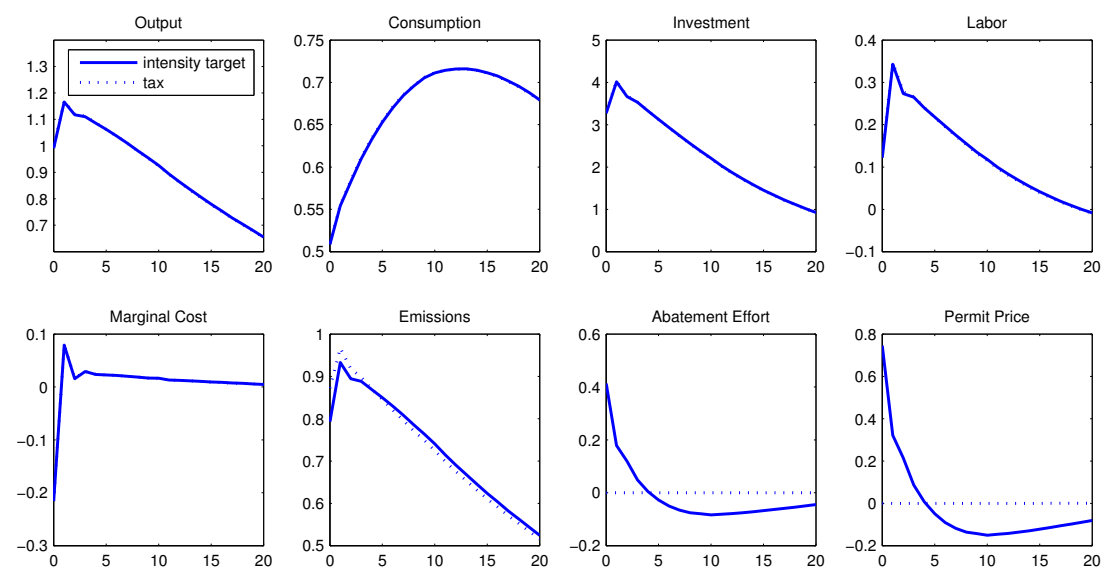

(b) Tax and Intensity Target 
Figure 2: Impulse Responses to a Public Consumption Shock
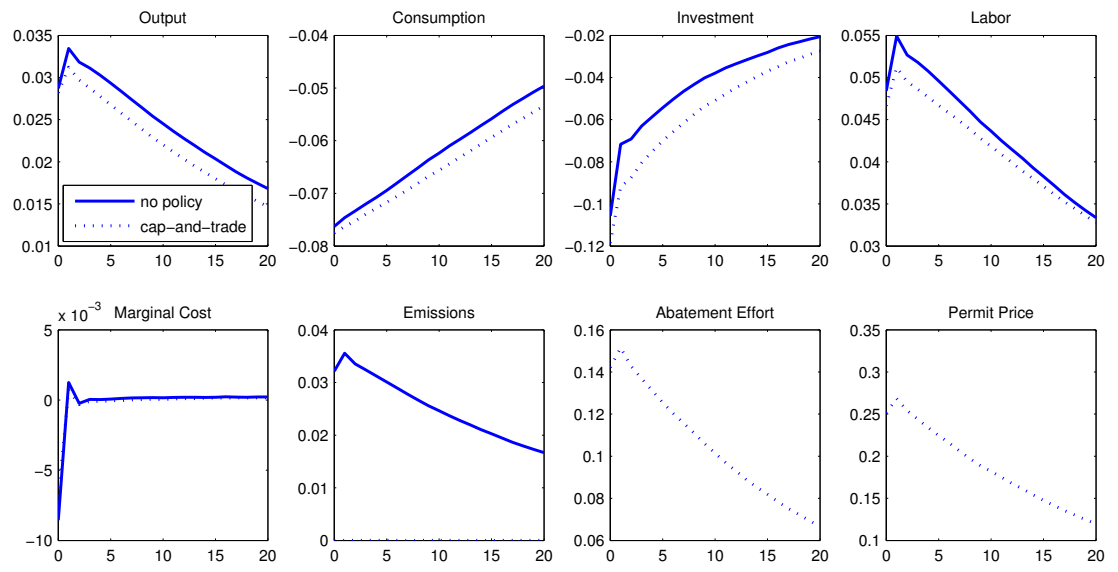

(a) No Policy and Cap-and-Trade
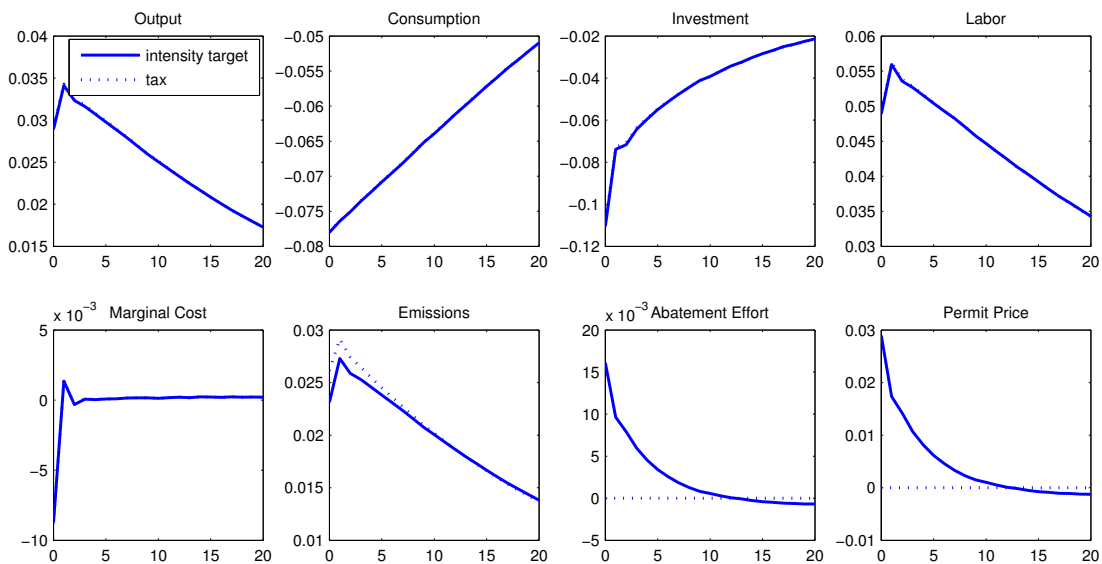

(b) Tax and Intensity Target 
Figure 3: Impulse Responses to a Monetary Policy Shock
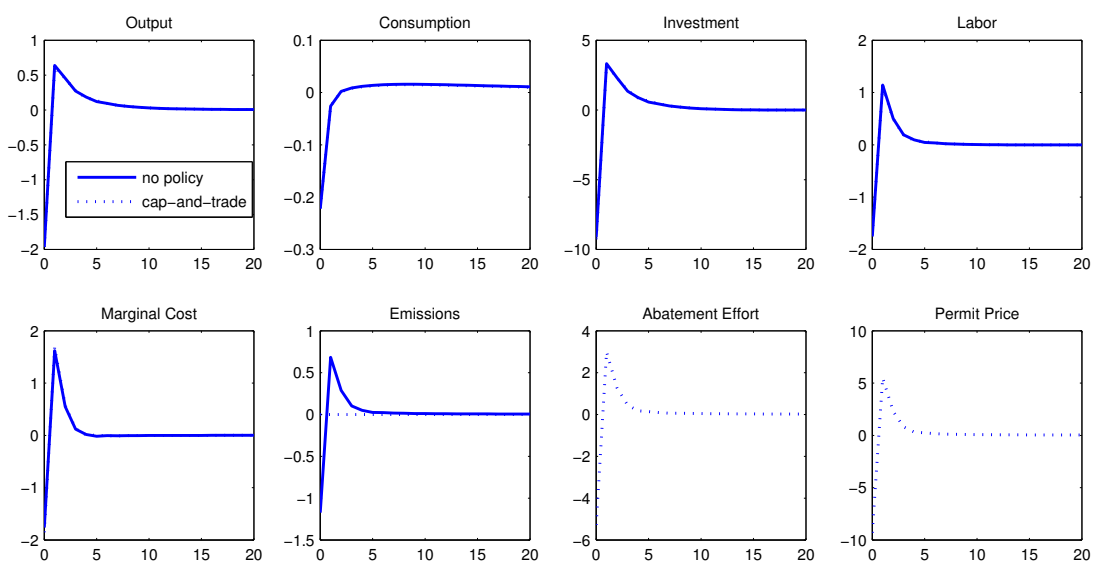

(a) No Policy and Cap-and-Trade
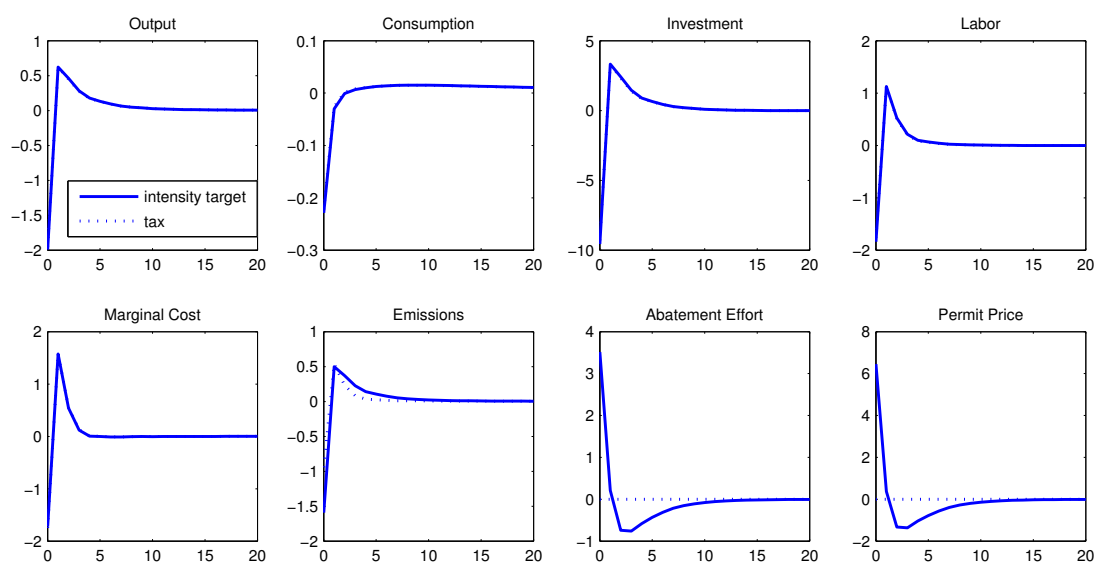

(b) Tax and Intensity Target 
Figure 4: Optimal Environmental Policy Response to Shocks and Nominal Rigidities
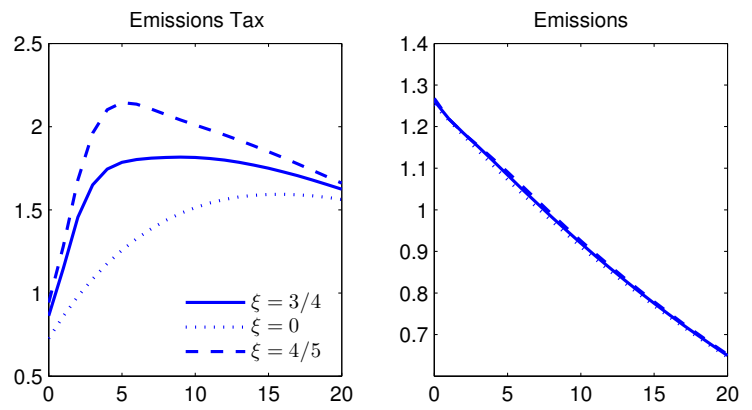

(a) Impulse Responses to a Technological Shock
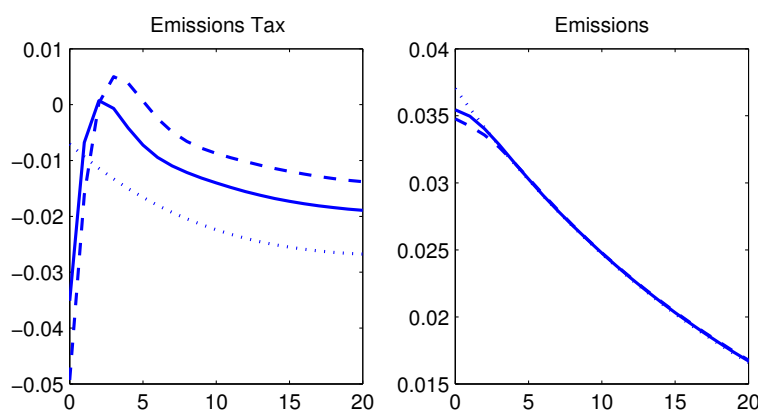

(b) Impulse Responses to a Public Consumption Shock
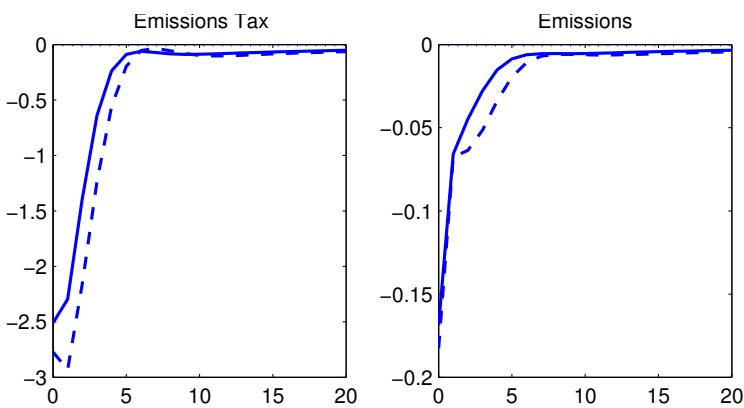

(c) Impulse Responses to a Monetary Policy Shock

Figure 5: Optimal Environmental Policy Response to Shocks for Different Monetary Regimes
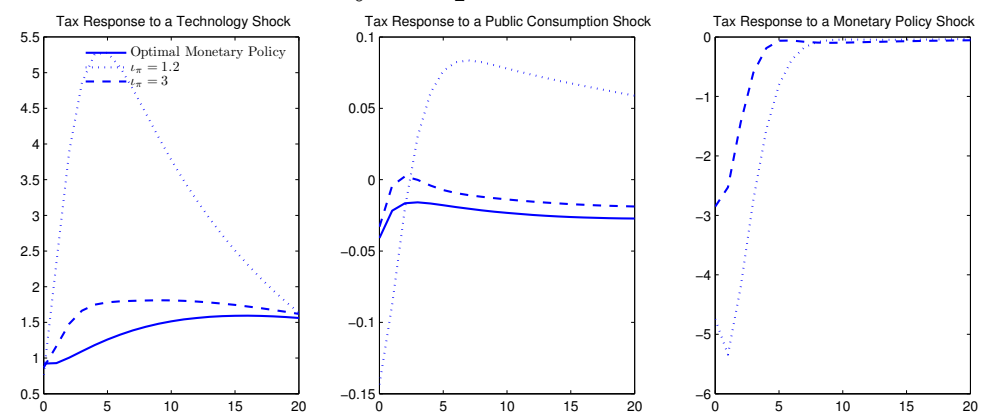